\title{
Morphological, Pathological, Biochemical and Molecular Characterization of Ralstonia solanacearum Isolates in Bangladesh
}

\author{
S. Razia1, M. S. M. Chowdhury ${ }^{1}$, F. M. Aminuzzaman ${ }^{*}{ }^{\circledR}$, N. Sultana ${ }^{1}$, M. Islam² \\ ${ }^{1}$ Department of Plant Pathology, Faculty of Agriculture, Sher-e-Bangla Agricultural University, Dhaka, Bangladesh \\ ${ }^{2}$ Plant Pathology Division, Bangladesh Agricultural Research Institute, Joydebpur, Gazipur, Bangladesh \\ Email:*aminsaupp@yahoo.com
}

How to cite this paper: Razia, S., Chowdhury, M.S.M., Aminuzzaman, F.M., Sultana, N. and Islam, M. (2021) Morphological, Pathological, Biochemical and Molecular Characterization of Ralstonia solanacearum Isolates in Bangladesh. American Journal of Molecular Biology, 11, 142-164.

https://doi.org/10.4236/ajmb.2021.114012

Received: July 12, 2021

Accepted: October 15, 2021

Published: October 18, 2021

Copyright $\odot 2021$ by author(s) and Scientific Research Publishing Inc. This work is licensed under the Creative Commons Attribution International License (CC BY 4.0).

http://creativecommons.org/licenses/by/4.0/

\section{(c) (i) Open Access}

\begin{abstract}
One thirty samples (fifty-five potato tubers, twenty-seven potato stems, three chili stems, twenty-eight soil samples, five weed samples, three banana leaves, and nine water samples) were examined and one hundred six (106) Bangladeshi isolates of Ralstonia solanacearum were isolated and identified. Isolation was made on selective media (Tetrazolium chloride media) and $R$. solanacearum was identified based on morphological, pathological and biochemical properties and polymerase chain reaction (PCR) by using the species-specific primers. Studies showed that $81.54 \%$ (106) samples were positive on tetrazolium chloride solid medium. Among them 90 isolates were virulent and rest of them were avirulent. Fifty isolates were selected for chemical characterization based on hypersensitivity test. $R$. solanacearum is gram negative, aerobic facultative bacteria on the basis of chemical characterization. Fifty tested isolates expressed as race 3 while in biovar test forty-eight showed as biovar III and the rest two showed as biovar I. In nine tested isolates from the three districts a species-specific band of $280 \mathrm{bp}$ was amplified in PCR that confirmed the identity of $R$. solanacerum.
\end{abstract}

\section{Keywords}

Brown Rot of Potato, Latent Infection, Ralstonia solanacearum, Biovar, Race

\section{Introduction}

R. solanacearum [1] formerly called Pseudomonas solanacearum [2] is the most destructive, damaging soil-borne pathogen [3] [4] [5]. Complex species [6] Ralstonia solanacearum is diversified and widely distributed with a wide host range 
including 44 families and more than 200 plant species [7] [8]. It is very destructive pathogen of potatoes in temperate, subtropical and tropical regions throughout the world [9] [10].

$R$. solanacearum is gram-negative, rod-shaped bacterium measuring $0.5-0.7$ $\times 1.5-2.0 \mu \mathrm{m}$ in size. This pathogen is severed at $24^{\circ} \mathrm{C}-35^{\circ} \mathrm{C}$ temperature but optimum at $28^{\circ} \mathrm{C}-32^{\circ} \mathrm{C}$ in aerobic conditions [11] [12]. Ralstonia solanacearum caused bacterial wilt, southern wilt and brown rot of potato world wide. Wilting and chlorosis of the leaves located at the tip of the branches are the first visible symptoms of $R$. solanacearum infection on potato (Solanum tuberosum), stunting and petiole epinasty may also occur due to the blocking of the vessels [13]. Infection of potato tubers with $R$. solanacearum may become latent under conducive environmental conditions [13].

$R$. solanacearum is historically sub divided into five races based on host range and five biovars based on different abilities to produce acid from a panel of a carbohydrate [7]. Race 1 hosts all solanaceous crops and many other plants which are available in Asia, Australia, America, Bangladesh, China, India, Japan, Nepal, Pakistan, Sri Lanka etc. belonged to biovar III, IV, and I; race 2 hosts triploid bananas, other Musa spp. are available in Caribbean, Brazil, Philippines which is belonged to biovar I; race 3 hosts only potato and tomato which is available worldwide except US and Canada belonged to biovar II or IIA; race 4 hosts ginger and unknown hosts available in Australia, China, Hawaii, India, Japan, Mauritius, South Asia and India belonged to biovar III and IV; and race 5 hosts mulberry tree in China which belongs to biovar V. However, typical race 3 strains are sometimes referred to as biovar IIA and new race 3 strains from the Amazon basin have been placed in a new biovar designed as IIT or NII and their relation to races is unclear [14] [15]. Based on the geographical distribution and interaction with climatic conditions, $R$. solanacearum was established in all agro-ecological zones of Bangladesh [16]. Ralstonia solanacearum caused the brown rot of potato found in Panchagar, Nilphamari, Rangpur, Lalmonirhat, Bogura, Joypurhat, Jashore and Rajshahi districts of Bangladesh [16]. The variation in $R$. solanacearum isolates of potato which was observed different growing region of Bangladesh that belonging to race 3 and biovar III [17] [18] [19].

Therefore, the objectives of this study were to 1 ) isolate and identify $R$. solanacearum from potato, chili, banana, soil and water in different potato growing areas of Bangladesh by morphological, pathological, biochemical and molecular tools and 2) to determine race and biovar of $R$. Solanacearum present in Bangladesh.

\section{Materials and Methods}

\subsection{Collection of Samples}

The sample collection was carried out in Munshiganj, Narayangonj and Nilphamari districts under nine upazila viz. Munshiganj Sadar, Tongibari, Sirajdikhan, Narayganj Sadar, Sonargaon, Rupgonj, Domar, Nilphamari Sadar and 
Dimla from the field, farmer storage and cold storage during May 2017 to November 2019 in Bangladesh. Samples were collected randomly from potato tubers, potato stems, chili stems, banana leaves, weed, soil and irrigation water. Symptoms of the disease were studied by visual observation as per standard procedure [10]. In order to increase the likelihood for detection sampling was made at least three replications [20]. Collected samples were put in polyethylene bags immediately after collection to protect them from drying. Labelling of each sample was done with the sample's location, date and sample identification number. Samples were carried to laboratory within 24 - 26 hours after collection for investigation.

\subsection{Observation of Visual Symptoms}

First samples were cleaned and then the collected samples were stored in the refrigerator between $4^{\circ} \mathrm{C}$ and $10^{\circ} \mathrm{C}$ [15] [20]. The infected tuber and plant samples were checked for oozing out which is the simple method by using sterilized knife and a tube containing sterilized distilled water [21] [22]. All collected samples identification of the disease was finally confirmed through isolation, different biochemical tests and molecular characterization.

\subsection{Isolation of Ralstonia solanacearum}

Ralstonia solanacearum were isolated by dilution plate method. The collected samples from potato tuber and stem washed with sterilized distilled water containing 1\% Clorox and then cut several small pieces. The cut surface was sterilized by dipping them in 5\% sodium hypochlorite solution for 2 - 3 minutes. It was then washed three times with sterile water. After surface sterilization, the cut pieces were kept in a test tube containing 3 - $4 \mathrm{ml}$ of sterile water and kept for 30 minutes for bacterial streaming and getting stock. $1 \mathrm{ml}$ of this stock solution was transferred with the help of sterile pipette into the second test tube containing 9 $\mathrm{ml}$ sterile water and shaken thoroughly for $10^{-1}$ dilution. Similarly, final dilution was made up to $10^{-4}$. Dried soil samples $(1 \mathrm{~g})$ were dissolved in $10 \mathrm{ml}$ of sterilized distilled water. The samples were agitated for 20 minutes and a dilution plate method $10^{-4}$ was then carried out. Collected water samples $(1 \mathrm{ml})$ were dissolved in $10 \mathrm{ml}$ of sterilized distilled water. The samples were shake for 20 minutes and dilution plate method $10^{-4}$ was accomplished. Weed and other crop (chilli) collar and root regions were segmented, rinsed, vortexed and dilution plate method $10^{-4}$ were brought off. Then $0.1 \mathrm{ml}$ solution directly placed on sterilized TZC [23] plates, incubated at growth chamber. 2, 3, 5-triphenyl tetrazolium chloride (TZC) selected media ( $1 \mathrm{~L})$ contained casamino acids ( $1.0 \mathrm{~g})$, peptone (10 g), glucose (5.0 g) and Agar (15 g). In TZC media $5 \mathrm{ml}$ of $1 \% 2,3$, 5-triphenyltetrazolium chloride was added to sterilized medium before pouring in to the plate [24]. The medium was cooled at $50^{\circ} \mathrm{C}-55^{\circ} \mathrm{C}$, poured into the petri plates and stored at $4^{\circ} \mathrm{C}$. The media was prepared following [14] [15] [22] [25] and was used to streak the bacterial suspension by using sterilized wire 
loop. Inoculated plates were incubated at $28^{\circ} \mathrm{C}-30^{\circ} \mathrm{C}$ for $2-3$ days in growth chamber. Plates should be incubated in an inverted position because water condensation causes colonies to flow into each other, thereby limiting separation. Separately growing colonies can then be picked and sub-cultured into fresh media to obtain pure cultures collected.

\subsection{Designation of Collected Isolates}

The collected isolates were designated based on their location and source of collection [26]. For example, an isolate designated by $\mathrm{PMMuTa}_{5} \mathrm{CS}_{01}$ represents that this isolate was collected from potato (P), district Munshiganj (M), Upazila Munshiganj Sadar $(\mathrm{Mu})$. Ta CS stands for Tamanna Cold Storage from where potato samples were collected. The sample collection number five is represented as $\mathrm{Ta}_{5}$. $\mathrm{CS}_{01}$ represents cold storage isolate number 01 . The details of the collected isolates were as follows: $\mathrm{PMMuTa}_{5} \mathrm{CS}_{01}=$ Potato tuber, Munshiganj, Munshiganj Sadar, Tamanna Cold Storage, Sample No.01; $\mathrm{PMMuFa}_{9} \mathrm{~S}_{06}=$ Potato tuber, Munshiganj, Munshiganj Sadar, Farmer Storage, Sample No. 06; $\mathrm{PMSiFi}_{3} \mathrm{CS}_{08}=$ Potato tuber, Munshiganj, Sirajdikhan, Five Star Cold Storage, Sample No. 08; $\mathrm{PMSiFa}_{2} \mathrm{~S}_{12}=$ Potato tuber, Munshiganj, Sirajdikhan, Farmer Storage, Sample No. 12; $\mathrm{PMTTo}_{5} \mathrm{CS}_{16}=$ Potato tuber, Munshiganj, Tongibari, Tongibari Cold Storage, Sample No. 16; PMTFa ${ }_{35} \mathrm{~S}_{21}=$ Potato tuber, Munshiganj, Tongibari, Farmer Storage, Sample No. 21; $\mathrm{PN}_{\mathrm{il}} \mathrm{DSh}_{43} \mathrm{CS}_{24}=$ Potato tuber, Nilphamari, Domar, Shawon Cold Storage, Sample No. 24; $\mathrm{PN}_{\mathrm{il}} \mathrm{DFa}_{7} \mathrm{~S}_{28}=$ Potato tuber, Nilphamari, Domar, Farmer Storage, Sample No. 28; $\mathrm{PN}_{\mathrm{il}} \mathrm{NiAn}_{19} \mathrm{CS}_{29}=$ Potato tuber, Nilphamari, Nilphamari Sadar, Ankur Cold Storage, Sample No. 29; $\mathrm{PN}_{\mathrm{il}} \mathrm{NiFa}_{2} \mathrm{~S}_{32}$ = Potato tuber, Nilphamari, Nilphamari Sadar, Farmer Storage, Sample No. 32; $\mathrm{PN}_{\mathrm{il}} \mathrm{DiMk}_{4} \mathrm{CS}_{33}=$ Potato tuber, Nilphamari, Dimla, Mukta Cold Storage, Sample No. 33; $\mathrm{PN}_{\mathrm{il}} \mathrm{DiFa}_{24} \mathrm{CS}_{36}=$ Potato tuber, Nilphamari, Dimla, Farmer Storage, Sample No. 36; $\mathrm{PNNaHa}_{2} \mathrm{CS}_{38}=$ Potato tuber, Narayangonj, Narayangonj Sadar, Hazi Rahamotolla Cold Storage, Sample No. 36; $\mathrm{PNNaFa}_{1} \mathrm{~S}_{43}=$ Potato tuber, Narayangonj, Narayangonj Sadar, Farmer Storage, Sample No. 43; $\mathrm{PNSSa}_{8} \mathrm{CS}_{45}=$ Potato tuber, Narayangonj, Sonargaon, Sahin Cold Storage, Sample No. 45; $\mathrm{PNSFa}_{20} \mathrm{~S}_{48}=$ Potato tuber, Narayangonj, Sonargaon, Farmer Storage, Sample No. 48; $\mathrm{PNRuMa}_{3} \mathrm{CS}_{50}=$ Potato tuber, Narayangonj, Rupgonj, Ma Cold Storage, Sample No. 50; $\mathrm{PNRuFa}_{4} \mathrm{~S}_{54}=$ Potato tuber, Narayangonj, Rupgonj, Farmer Storage, Sample No. 54; $\mathrm{P}_{1} \mathrm{MMuF}_{6} \mathrm{~S}_{01}=$ Potato plant, Munshiganj, Munshiganj Sadar, Field, Sample No. 01; $\mathrm{P}_{1} \mathrm{MSiF}_{33} \mathrm{~S}_{04}=$ Potato plant, Munshiganj, Sirajdikhan, Field, Sample No. 04; $\mathrm{P}_{1} \mathrm{MTF}_{9} \mathrm{~S}_{07}=$ Potato plant, Munshiganj, Tongibari, Field, Sample No. 07; $\mathrm{P}_{1} \mathrm{~N}_{\mathrm{il}} \mathrm{DF}_{11} \mathrm{~S}_{10}=$ Potato plant, Nilphamari, Domar, Field, Sample No. 10; $\mathrm{P}_{1} \mathrm{~N}_{\mathrm{il}} \mathrm{NiF}_{19} \mathrm{~S}_{13}=$ Potato plant, Nilphamari, Nilphamari Sadar, Field Sample No. 13; $\mathrm{P}_{1} \mathrm{~N}_{\mathrm{il}} \mathrm{DiF}_{7} \mathrm{~S}_{16}=$ Potato plant, Nilphamari, Dimla, Field, Sample No. 16; $\mathrm{P}_{1} \mathrm{NNaF}_{3} \mathrm{~S}_{19}=$ Potato plant, Narayangonj, Narayangonj Sadar, Field, Sample No. 19; $\mathrm{P}_{1} \mathrm{NSF}_{4} \mathrm{~S}_{22}$ = Potato plant, Narayangonj, Sonargaon, Field, Sample No. 22; $\mathrm{P}_{1} \mathrm{NRuF}_{3} \mathrm{~S}_{25}=$ Potato plant, Narayangonj, Rupgonj, Field, Sample No. 25; $\mathrm{CNRF}_{14} \mathrm{~S}_{01}=$ Chilli, Narayangonj, Rupgonj, Field, Sample No. 01; SoMMuF $\mathrm{S}_{01}=$ 
Soil, Munshiganj, Munshiganj Sadar, Field, Sample No. 01; SoMSiF $\mathrm{S}_{04}=$ Soil, Munshiganj, Sirajdikhan, Field, Sample No. 04; $\mathrm{SoMToF}_{1} \mathrm{~S}_{07}=$ Soil, Munshiganj, Tongibari, Field, Sample No. 07; $\mathrm{SoN}_{\mathrm{il}} \mathrm{DF}_{1} \mathrm{~S}_{11}=$ Soil, Nilphamari, Domar, Field, Sample No. 11; $\mathrm{SoN}_{\mathrm{il}} \mathrm{NiF}_{1} \mathrm{~S}_{14}$ = Soil, Nilphamari, Nilphamari Sadar, Field, Sample No. 14; $\mathrm{SoN}_{\mathrm{il}} \mathrm{DiF}_{1} \mathrm{~S}_{17}=$ Soil, Nilphamari, Dimla, Field, Sample No. 17; SoN$\mathrm{NaF}_{1} \mathrm{~S}_{20}=$ Soil, Narayangonj, Narayangonj Sadar, Field, Sample No. 20; SoNSF $_{1} \mathrm{~S}_{23}=$ Soil, Narayangonj, Sonargaon, Field, Sample No. 23; SoNRuF $\mathrm{S}_{26}=$ Soil, Narayangonj, Rupgonj, Field, Sample No. 26; $\mathrm{WMSiF}_{13} \mathrm{~S}_{01}=$ Weed, Munshigonj, Sirajdikhan, Field, Sample No. 01; $\mathrm{WN}_{\mathrm{il}} \mathrm{NiF}_{16} \mathrm{~S}_{03}=$ Weed, Nilphamari, Nilphamari Sadar, Field, Sample No. 03; $\mathrm{WNRuFa}_{36} \mathrm{~S}_{05}=$ Weed, Narayangonj, Rupgonj, Field, Sample No. 05; $\mathrm{BNRF}_{2} \mathrm{~S}_{01}=$ Banana, Narayangonj, Rupgonj, Field, Sample No. 01; $\mathrm{WaMSiF}_{1} \mathrm{~S}_{01}=$ Water, Munshigonj, Sirajdikhan, Field, Sample No. 01; $\mathrm{WaN}_{\mathrm{il}} \mathrm{NiF}_{11} \mathrm{~S}_{04}=$ Water, Nilphamari, Nilphamari Sadar, Field, Sample No. 04; $\mathrm{WaNRuF}_{1} \mathrm{~S}_{07}=$ Water, Narayangonj, Rupgonj, Field, Sample No. 07.

\subsection{Hypersensitive Reaction}

Hypersensitive reaction was performed on the leaf of Nicotiana tabacum [27] [28]. At 30 - 40 days aged tobacco plants were selected for inoculation. Single colony of $R$. solanacearum showing virulent, fluidal, irregular and creamy white with pink at the centre was selected for each isolate and multiplied in a CPG (without adding triphenyl tetrazolium chloride) medium for $48 \mathrm{~h}$ prior to inoculation. Bacterial suspensions were prepared in distilled sterilized water and $10^{8}$ $\mathrm{cfu} / \mathrm{mL}$, cell density was adjusted through benchtop spectrophotometer at 620 $\mathrm{nm}$. $1 \mathrm{ml}$ plastic syringe with $25 \mathrm{~mm}$ gauge needles was used to inject cell suspension into the abaxial side of the mature tobacco leaves. Alternating interveinal regions were infiltrated with bacterial suspension. Each injected area was labelled with appropriate letters. A fine mist of water was lightly sprayed over the whole plants and placed at room temperature $\left(25^{\circ} \mathrm{C}-27^{\circ} \mathrm{C}\right)$. Plants were covered with clear plastic bags. Data were recorded 1, 3 and 7 days after inoculations [28].

\subsection{Biochemical Test}

Hypersensative reaction positive isolates were studied according to specific six biochemical tests for Ralstonia solanacearum.

\subsubsection{Gram Staining}

Young pure cultures ( $24 \mathrm{hrs}$ ) were used for gram-staining. A loop of the bacterium was spreaded on a glass slide and fixed by heating on a very low flame. Aqueous crystal violet solution (0.5\%) was spread over the smear for 30 seconds and then washed with running tape water for one minute. It was then flooded with iodine for one minute, rinsed in tape water and decolorized with 95\% ethanol until colourless runoff. After washing the specimen was counter-stained with safranin for approximately 10 seconds, washed with water, dried and ob- 
served microscopically at 10X, 40X and 100X using oil imersion [29].

\subsubsection{Potassium Hydroxide (KOH) Test}

Isolates of $R$. solanacearum were aseptically taken from 24 - 36 hrs old culture plates with a sterile tooth pick. It was then placed on glass slide in a drop of $3 \%$ $\mathrm{KOH}$ solution, stirred for 10 seconds and observed for the formation of slime threads [30].

\subsubsection{Catalase 0xidase Test}

Catalase test was performed with isolates to check their liveliness. Young agar cultures (18 - $24 \mathrm{hrs})$ and $3 \%$ hydrogen peroxide $\left(\mathrm{H}_{2} \mathrm{O}_{2}\right)$ were used to observe production of gas bubbles. A loop full of bacterial culture was mixed with a drop of $\mathrm{H}_{2} \mathrm{O}_{2}$ on a glass slide and observed for the production of gas bubbles with naked eye and under a dissecting magnification of 25X [29].

\subsubsection{Kovac's Oxidase Test}

Oxidase reagent (1\% tetramethyl-p-phenyl diamine dihydrochloride) solution $(100 \mathrm{ml})$ was prepared and kept in rubber-stopper dark bottle. A drop of reagent was added to a piece of filter paper (whatman no. 1) placed within a glass petri dish. Small quantities of the inoculum were rubbed on the filter paper impregnated with $1 \%(\mathrm{w} / \mathrm{v})$ oxidase reagent solution. Bacteria were then noted for the development of purple colour in 10 - 60 seconds indicating the oxidation of the reagent [25].

\subsubsection{Pectolytic Test}

Potato tubers were disinfected with $99 \%$ ethanol, cut up into slices of about $7-8$ $\mathrm{mm}$ thick, and then placed on moistened sterile filter paper in sterile petri dishes. Bacterial cell suspension was pipetted into a depression cut in the potato slices. One potato slice pipetted with sterile water was treated as control. Development of rot on the slices was examined $24-48 \mathrm{~h}$ after incubation at $25^{\circ} \mathrm{C}$. Examination was done 5 days after inoculation. Two slices were inoculated for each isolate [25] [31] [32].

\subsubsection{Temperature Sensitivity Test}

The ability of bacterial isolates to grow at different selected temperature. Bacterial suspensions from different isolates were prepared from 24 hrs TZC cultures and 2 - 3 drops of suspension were plated on TZC medium which was placed at $4^{\circ} \mathrm{C} \pm 2^{\circ} \mathrm{C}, 28^{\circ} \mathrm{C} \pm 2{ }^{\circ} \mathrm{C}, 37^{\circ} \mathrm{C} \pm 2^{\circ} \mathrm{C}$ and $40^{\circ} \mathrm{C} \pm 2^{\circ} \mathrm{C}$ temperatures [25].

\subsection{PCR for Molecular Confirmation of $R$. solanacearum Isolates}

The isolates of $R$. solanacearum collected from Munshingonj, Narayngonj and Nilphamari districts were tested for molecular detection. Three isolates from each district were selected and confirmed by polymerase chain reaction (PCR) technique using 1 kb DNA ladder (Promega, USA, dispensed Lot \# 0000339931) on agarose gel. A pair of universal species-specific primer pair AU759f (5'-GTC 
GCC GTC AAC TCA CTT TCC-3') and AU760r (5'-GTC GCC GTC AGC AAT GCG GAA TCG-3') were used [33]. A well separated bacterial colony on TZC medium were cultured on CPG broth (Peptone $10 \mathrm{~g}$; glucose, $5 \mathrm{~g}$; Casamino acid, $1 \mathrm{~g}$; distilled water $1 \mathrm{l} ; \mathrm{pH} 7.0-7.1$ ) and incubated at $28^{\circ} \mathrm{C}$ for $48-72 \mathrm{~h}$ with vigorous shaking prior to the DNA extraction process in a shaking incubator. Genomic DNA extracted by Gene JET Genomic DNA Purification Kit from Thermo Fisher Scientific (www.thermoscientific.com/onebio). PCR amplification was carried out in a total volume of $25 \mu \mathrm{l}$ using $12 \mu \mathrm{l}$ of PCR Master Mix (Thermo fisher), $1 \mu \mathrm{l}$ of forward primer, $1 \mu \mathrm{l}$ of rivers primer, $5 \mu \mathrm{l}$ of genomic DNA and $6 \mu$ Milli $Q$ water. The following cycling program was used in a thermal cycler: an initial denaturation step at $95^{\circ} \mathrm{C}$ for 5 mins, followed by 35 cycles of $95^{\circ} \mathrm{C}$ for $30 \mathrm{~s}, 57^{\circ} \mathrm{C}$ for $45 \mathrm{~s}$ and $72^{\circ} \mathrm{C}$ for $45 \mathrm{~s}$, followed by a final extension step of $72^{\circ} \mathrm{C}$ for 5 mins. After completion of cycling program, reaction was held at $4^{\circ} \mathrm{C}$. Bacterial suspensions of $R$. solanacearum at approximately $10^{9} \mathrm{CFU} / \mathrm{ml}$ and sterile water were used as the positive and negative control, respectively. PCR product of expected $280 \mathrm{bp}$ was visualized under UV light after electrophoresis in $1.5 \%$ agarose and staining in ethidium bromide solution $\left(1 \mu \mathrm{g} \cdot \mathrm{ml}^{-1}\right)$ and photographed.

\subsection{Race Determination}

The races of $R$. solanacearum were determined by pathogenicity test on wide host range [34] [35]. Soil was prepared by integration of farmyard manure, sand and clay in 1:1:1 ratio. This mixture was sterilized by $37 \%$ formalin in 1:9 ratio (1 part formalin and 9 parts soil). Soil mixture was covered with polyethylene sheet and kept for 4 days. After that the polyethylene sheet was removed and treated soil was exposed in air for additional two days. Plastic tray was filled by sterilized soil. Potato (Solanum tuberosum), tomato (Solanum lycopersicum) and brinjal (Solanum melongena) seeds were surface sterilized, rinsed with sterile water and sown in separate tray. Seedlings bearing $4 / 5$ leaves were used for performing pathogenicity tests through artificial inoculation and race assinged [36]. The seedlings were inoculated with $R$. solanacearum by wounded root dippingin bacterial suspension for 30 mins [25] [28] [37] [38]. Plants were not watered a day before inoculation to reduce moisture in the pots. Roots of potato, tomato and brinjal seedlings were slightly injured by inserting a scalpel in the pots in order to facilitate bacterial infection. About $10 \mathrm{ml}$ of bacterial suspension $\left(10^{8}\right.$ $\mathrm{cfu} / \mathrm{mL}$ ) of each isolate was used for the study. Inoculated plants were regularly watered and kept at temperature range from $28^{\circ} \mathrm{C}-30^{\circ} \mathrm{C}$ and $90 \% \mathrm{RH}$ [39]. The inoculated plants were then kept in observation until the symptoms were developed.

\subsection{Biovar Test}

Biovars of $R$. solanacearum was determined on the basis of carbon utilization in disaccharides and hexose alcohols [7] [35]. The disaccharides were cellobiose, 
lactose, and maltose while the hexose alcohols were dulcitol, mannitol and sorbitol. Sterilized solutions $(10 \% \mathrm{~W} / \mathrm{V})$ of these carbon sources were added to a basal medium (Table 1) before inoculation of $R$. solanacearum isolates.

The medium was brought to boil with constant stirring and raised the $\mathrm{pH}$ of the medium to $7.0-7.1$ by drop wise addition of $1.0 \mathrm{~N}$ sodium hydroxide. When the medium turned green, the medium was then autoclaved at $121^{\circ} \mathrm{C}, 15 \mathrm{psi}$ for 20 mins.

Cellobiose, lactose, maltose, dulcitol, mannitol and sorbitol were taken $1 \mathrm{~g}$ from each disaccharide and hexose alcohols were dissolved in $10 \mathrm{ml}$ distilled water separately. Solutions were filter-sterilized using $0.22 \mu \mathrm{m}$ filters.

After autoclaving, the basal medium was cooled at $65^{\circ} \mathrm{C} .10 \mathrm{ml}$ each of disaccharides and hexose alcohols solutions were mixed with $90 \mathrm{ml}$ basal medium. For the control, $10 \mathrm{ml}$ sterile water was mixed (without disaccharides and hexose alcohols) with $90 \mathrm{ml}$ basal medium. The media containing $1 \%$ of each disaccharide and hexose alcohols was prepared to determine the biovars of isolates of $R$. solanacearum [40]. After melting the medium, it was then dispensed into the wells of microtiter plate.

Isolates of $R$. solanacearum were grown on CPG solid media to test the biovar expression on the basis of carbon utilization in disaccharides and hexose alcohols which were incubated in $28^{\circ} \mathrm{C}$ temperature [7] [15] [22] [35]. CPG media compounds were tabulated in Table 2.

The ingredients were autoclaved at $121^{\circ} \mathrm{C}$ for 15 mins and cool to about $40^{\circ} \mathrm{C}$ $45^{\circ} \mathrm{C}$ before pouring. The homogenized medium was then poured into sterile petri dishes and let solidify for 30 mins. Isolates of $R$. solanacearum were then taken from pure culture to dilute @10 microliters $/ \mathrm{ml}$ and spread plated and incubated at optimum temperature. Inocula for each isolate were prepared by adding a loopful of the bacteria from $24-48 \mathrm{~h}$ old cultures to $1 \mathrm{ml}$ sterile in a 2.0 $\mathrm{ml}$ centrifuge tube. One small drop of cloudy bacterial suspension was added in each well of a column. After inoculation microtiter plate incubated at $28^{\circ} \mathrm{C}$. Reactions were observed and recorded after seven days of inoculation. A colour change to yellow (acid $\mathrm{pH}<6$ ) indicates oxidation of the carbon source [7] [41]. This usually occurs within 3 - 5 days; those biovars capable of oxidizing disaccharides take a few days longer to give a clear positive result. The inoculated tubes compared with a non-inoculated control tube.

\section{Results}

It was observed that fifty-five tuber samples showed positive in oozing and browning in vascular bundle (Table 3). In streaming test, it was observed that twenty-seven potato plant samples showed positive bacterial ooze streaming in clear water but three chilli samples showed negetive in streaming test (Table 3). Selected weed, soil, banana and water samples did not show any streaming and oozing test. Twenty-eight soil samples, five weed samples, three banana samples and nine water samples were also used to isolation of Ralstonia solanacearum (Table 3). 
Table 1. Components for preparing basal medium.

\begin{tabular}{cc}
\hline Components & Per $1000 \mathrm{ml}$ distilled water liter $^{-1}$ \\
\hline Ammonium dihydrogen phosphate $\left(\mathrm{NH}_{4} \mathrm{H}_{2} \mathrm{PO}_{4}\right)$ & $1.0 \mathrm{~g}$ \\
Potassium chloride $(\mathrm{KCl})$ & $0.2 \mathrm{~g}$ \\
Magnesium sulphate $\left(\mathrm{MgSO}_{4} \cdot 7 \mathrm{H}_{2} \mathrm{O}\right)$ & $0.2 \mathrm{~g}$ \\
Peptone & $1.0 \mathrm{~g}$ \\
Bromothymol blue & $0.03 \mathrm{~g}$ \\
Agar & $3.0 \mathrm{~g}$ \\
Water & $1.0 \mathrm{~L}$ \\
\hline
\end{tabular}

Table 2. Component of CPG medium.

\begin{tabular}{cc}
\hline Components & Per $1000 \mathrm{ml}$ distilled water liter $^{-1}$ \\
\hline Casamino acids (Difco) & $1.0 \mathrm{~g}$ \\
Bacto-Peptone (Difco) & $10.0 \mathrm{~g}$ \\
Glucose & $10.0 \mathrm{~g}$ \\
Bacto-Agar (Difco) & $18.0 \mathrm{~g}$ \\
\hline
\end{tabular}

Table 3. Host and sources of collected isolates of $R$. solanacearum from Bangladesh and their reaction response on TZC, virulent colony (VC) and hypersensitivity (HR) test.

\begin{tabular}{|c|c|c|c|c|c|}
\hline Isolates & source & Host & TZC & VC & $\begin{array}{l}\text { HR } \\
\text { test }\end{array}$ \\
\hline $\mathrm{PMMuTa}_{5} \mathrm{CS}_{01}$ & \multirow{5}{*}{$\begin{array}{l}\text { Munshiganj, Munshiganj Sadar } \\
\text { (Tamanna Cold Storage) }\end{array}$} & \multirow{5}{*}{ Solanum tuberosum } & $+\mathrm{ve}$ & $+\mathrm{ve}$ & $+\mathrm{ve}$ \\
\hline $\mathrm{PMMuTa}_{11} \mathrm{CS}_{02}$ & & & $+\mathrm{ve}$ & $+\mathrm{ve}$ & $-\mathrm{ve}$ \\
\hline $\mathrm{PMMuTa}_{17} \mathrm{CS}_{03}$ & & & $+\mathrm{ve}$ & $-\mathrm{ve}$ & - \\
\hline $\mathrm{PMMuTa}_{19} \mathrm{CS}_{04}$ & & & $+\mathrm{ve}$ & $+\mathrm{ve}$ & + ve \\
\hline $\mathrm{PMMuTa}_{23} \mathrm{CS}_{05}$ & & & -ve & -ve & - \\
\hline $\begin{array}{l}\mathrm{PMMuFa}_{9} \mathrm{~S}_{06} \\
\mathrm{PMMuFa}_{15} \mathrm{~S}_{07}\end{array}$ & $\begin{array}{l}\text { Munshiganj, Munshiganj Sadar } \\
\text { (Farmer Storage) }\end{array}$ & Solanum tuberosum & $\begin{array}{l}+\mathrm{ve} \\
+\mathrm{ve}\end{array}$ & $\begin{array}{l}\text {-ve } \\
+ \text { ve }\end{array}$ & $\begin{array}{l}- \\
+\mathrm{ve}\end{array}$ \\
\hline $\mathrm{PMSiFi}_{3} \mathrm{CS}_{08}$ & \multirow{4}{*}{$\begin{array}{l}\text { Munshiganj, Sirajdikhan } \\
\text { (Five Star Cold Storage) }\end{array}$} & \multirow{4}{*}{ Solanum tuberosum } & $+\mathrm{ve}$ & $+\mathrm{ve}$ & +ve \\
\hline $\mathrm{PMSiFi}_{11} \mathrm{CS}_{09}$ & & & & $+\mathrm{ve}$ & $-\mathrm{ve}$ \\
\hline $\mathrm{PMSiFi}_{21} \mathrm{CS}_{10}$ & & & $+\mathrm{ve}$ & +ve & $+\mathrm{ve}$ \\
\hline $\mathrm{PMSiFi}_{24} \mathrm{CS}_{11}$ & & & $+\mathrm{ve}$ & -ve & - \\
\hline $\mathrm{PMSiFa}_{2} \mathrm{~S}_{12}$ & \multirow{4}{*}{$\begin{array}{l}\text { Munshiganj, Sirajdikhan } \\
\text { (Farmer Storage) }\end{array}$} & \multirow{4}{*}{ Solanum tuberosum } & $+\mathrm{ve}$ & $+\mathrm{ve}$ & $+\mathrm{ve}$ \\
\hline $\mathrm{PMSiFa}_{12} \mathrm{~S}_{13}$ & & & $+\mathrm{ve}$ & -ve & - \\
\hline $\mathrm{PMSiFa}_{22} \mathrm{~S}_{14}$ & & & $+\mathrm{ve}$ & -ve & - \\
\hline $\mathrm{PMSiFa}_{28} \mathrm{~S}_{15}$ & & & +ve & +ve & +ve \\
\hline $\mathrm{PMTTo}_{5} \mathrm{CS}_{16}$ & \multirow{5}{*}{$\begin{array}{l}\text { Munshiganj, Tongibari } \\
\text { (Tongibari Cold Storage) }\end{array}$} & \multirow{5}{*}{ Solanum tuberosum } & $+\mathrm{ve}$ & $+\mathrm{ve}$ & -ve \\
\hline $\mathrm{PMTTo}_{7} \mathrm{CS}_{17}$ & & & $+\mathrm{ve}$ & $-\mathrm{ve}$ & - \\
\hline $\mathrm{PMTTo}_{15} \mathrm{CS}_{18}$ & & & $+\mathrm{ve}$ & +ve & +ve \\
\hline $\mathrm{PMTTo}_{18} \mathrm{CS}_{19}$ & & & $+\mathrm{ve}$ & -ve & - \\
\hline $\mathrm{PMTTo}_{20} \mathrm{CS}_{20}$ & & & $+\mathrm{ve}$ & $+\mathrm{ve}$ & $+\mathrm{ve}$ \\
\hline
\end{tabular}




\section{Continued}

\begin{tabular}{|c|c|c|c|c|c|}
\hline $\mathrm{PMTFa}_{35} \mathrm{~S}_{21}$ & \multirow{3}{*}{ Munshiganj, Tongibari (Farmer) } & \multirow{3}{*}{ Solanum tuberosum } & $+\mathrm{ve}$ & + ve & + ve \\
\hline $\mathrm{PMTFa}_{36} \mathrm{~S}_{22}$ & & & $+\mathrm{ve}$ & $-\mathrm{ve}$ & - \\
\hline $\mathrm{PMTFa}_{41} \mathrm{~S}_{23}$ & & & +ve & $+\mathrm{ve}$ & $+\mathrm{ve}$ \\
\hline $\mathrm{PN}_{\mathrm{il}} \mathrm{DSh}_{43} \mathrm{CS}_{24}$ & \multirow{4}{*}{$\begin{array}{l}\text { Nilphamari, Domar } \\
\text { (Shawon Cold Storage) }\end{array}$} & \multirow{4}{*}{ Solanum tuberosum } & -ve & $-\mathrm{ve}$ & - \\
\hline $\mathrm{PN}_{\mathrm{il}} \mathrm{DSh}_{46} \mathrm{CS}_{25}$ & & & $+\mathrm{ve}$ & $+\mathrm{ve}$ & $+\mathrm{ve}$ \\
\hline $\mathrm{PN}_{\mathrm{il}} \mathrm{DSh}_{47} \mathrm{CS}_{26}$ & & & +ve & $+\mathrm{ve}$ & $-\mathrm{ve}$ \\
\hline $\mathrm{PN}_{\mathrm{il}} \mathrm{DSh}_{50} \mathrm{CS}_{27}$ & & & +ve & $+\mathrm{ve}$ & $+\mathrm{ve}$ \\
\hline $\mathrm{PN}_{\mathrm{il}} \mathrm{DFa}_{7} \mathrm{~S}_{28}$ & Nilphamari, Domar (Farmer) & Solanum tuberosum & $+\mathrm{ve}$ & + ve & $-v e$ \\
\hline $\mathrm{PN}_{\mathrm{il}} \mathrm{NiAn}_{19} \mathrm{CS}_{29}$ & \multirow{3}{*}{$\begin{array}{l}\text { Nilphamari, Nilphamari Sadar } \\
\text { (Ankur Cold Storage) }\end{array}$} & \multirow{3}{*}{ Solanum tuberosum } & $+\mathrm{ve}$ & $-\mathrm{ve}$ & - \\
\hline $\mathrm{PN}_{\mathrm{il}} \mathrm{NiAn}_{31} \mathrm{CS}_{30}$ & & & $+\mathrm{ve}$ & +ve & + ve \\
\hline $\mathrm{PN}_{\mathrm{il}} \mathrm{NiAn}_{31} \mathrm{CS}_{31}$ & & & +ve & $-\mathrm{ve}$ & - \\
\hline $\mathrm{PN}_{\mathrm{il}} \mathrm{NiFa}_{2} \mathrm{~S}_{32}$ & $\begin{array}{l}\text { Nilphamari, Nilphamary Sadar } \\
\text { (Farmer Storage) }\end{array}$ & Solanum tuberosum & +ve & $+\mathrm{ve}$ & $-\mathrm{ve}$ \\
\hline $\mathrm{PN}_{\mathrm{il}} \mathrm{DiMk}_{4} \mathrm{CS}_{33}$ & \multirow{3}{*}{$\begin{array}{l}\text { Nilphamari, Dimla (Mukta Cold } \\
\text { Storage) }\end{array}$} & \multirow{3}{*}{ Solanum tuberosum } & +ve & $+\mathrm{ve}$ & +ve \\
\hline $\mathrm{PN}_{\mathrm{il}} \mathrm{DiMk}_{14} \mathrm{CS}_{34}$ & & & $+\mathrm{ve}$ & - ve & - \\
\hline $\mathrm{PN}_{\mathrm{il}} \mathrm{DiMk}_{17} \mathrm{CS}_{35}$ & & & +ve & $+\mathrm{ve}$ & $+\mathrm{ve}$ \\
\hline $\mathrm{PN}_{\mathrm{il}} \mathrm{DiFa}_{24} \mathrm{CS}_{36}$ & \multirow{2}{*}{$\begin{array}{l}\text { Nilphamari, Dimla } \\
\text { (Farmer Storage) }\end{array}$} & \multirow{2}{*}{ Solanum tuberosum } & $+\mathrm{ve}$ & + ve & - ve \\
\hline $\mathrm{PN}_{\mathrm{il}} \mathrm{DiFa}_{29} \mathrm{CS}_{37}$ & & & +ve & $+\mathrm{ve}$ & $+\mathrm{ve}$ \\
\hline $\mathrm{PNNaHa}_{2} \mathrm{CS}_{38}$ & \multirow{5}{*}{$\begin{array}{l}\text { Narayangonj, Narayangonj Sadar } \\
\text { (Hazi Rahamotolla Cold Storage) }\end{array}$} & \multirow{5}{*}{ Solanum tuberosum } & +ve & $+\mathrm{ve}$ & $+\mathrm{ve}$ \\
\hline $\mathrm{PNNaHa}_{13} \mathrm{CS}_{39}$ & & & -ve & -ve & - \\
\hline $\mathrm{PNNaHa}_{15} \mathrm{CS}_{40}$ & & & +ve & +ve & $+\mathrm{ve}$ \\
\hline $\mathrm{PNNaHa}_{16} \mathrm{CS}_{41}$ & & & $+\mathrm{ve}$ & $+\mathrm{ve}$ & $-\mathrm{ve}$ \\
\hline $\mathrm{PNNaHa}_{21} \mathrm{CS}_{42}$ & & & +ve & $-\mathrm{ve}$ & - \\
\hline $\mathrm{PNNaFa}_{1} \mathrm{~S}_{43}$ & \multirow{2}{*}{$\begin{array}{l}\text { Narayangonj, Narayangonj Sadar } \\
\text { (Farmer Storage) }\end{array}$} & \multirow{2}{*}{ Solanum tuberosum } & +ve & +ve & - ve \\
\hline $\mathrm{PNNaFa}_{11} \mathrm{~S}_{44}$ & & & +ve & $+\mathrm{ve}$ & $+\mathrm{ve}$ \\
\hline $\mathrm{PNSSa}_{8} \mathrm{CS}_{45}$ & \multirow{3}{*}{$\begin{array}{l}\text { Narayangonj, Sonargaon } \\
\text { (Sahin Cold Storage) }\end{array}$} & \multirow{3}{*}{ Solanum tuberosum } & +ve & +ve & -ve \\
\hline $\mathrm{PNSSa}_{9} \mathrm{CS}_{46}$ & & & +ve & +ve & +ve \\
\hline $\mathrm{PNSSa}_{15} \mathrm{CS}_{47}$ & & & $+\mathrm{ve}$ & -ve & - \\
\hline $\mathrm{PNSFa}_{20} \mathrm{~S}_{48}$ & \multirow{2}{*}{$\begin{array}{l}\text { Narayangonj, Sonargaon } \\
\text { (Farmer Storage) }\end{array}$} & \multirow[t]{2}{*}{ Solanum tuberosum } & $+\mathrm{ve}$ & $+\mathrm{ve}$ & $+\mathrm{ve}$ \\
\hline $\mathrm{PNSFa}_{25} \mathrm{~S}_{49}$ & & & +ve & $+\mathrm{ve}$ & -ve \\
\hline $\mathrm{PNRuMa}_{3} \mathrm{CS}_{50}$ & \multirow{4}{*}{$\begin{array}{l}\text { Narayangonj, Rupgonj } \\
\text { (Ma Cold Storage) }\end{array}$} & \multirow{4}{*}{ Solanum tuberosum } & +ve & $+\mathrm{ve}$ & $+\mathrm{ve}$ \\
\hline $\mathrm{PNRuMa}_{7} \mathrm{CS}_{51}$ & & & +ve & $+\mathrm{ve}$ & +ve \\
\hline $\mathrm{PNRuMa}_{13} \mathrm{CS}_{52}$ & & & $+\mathrm{ve}$ & $+\mathrm{ve}$ & $-\mathrm{ve}$ \\
\hline $\mathrm{PNRuMa}_{19} \mathrm{CS}_{53}$ & & & +ve & +ve & +ve \\
\hline $\mathrm{PNRuFa}_{4} \mathrm{~S}_{54}$ & \multirow{2}{*}{$\begin{array}{l}\text { Narayangonj, Rupgonj } \\
\quad \text { (Farmer Storage) }\end{array}$} & \multirow[t]{2}{*}{ Solanum tuberosum } & $+\mathrm{ve}$ & $+\mathrm{ve}$ & -ve \\
\hline $\mathrm{PNRuFa}_{4} \mathrm{~S}_{55}$ & & & -ve & -ve & - \\
\hline $\mathrm{P}_{1} \mathrm{MMuF}_{6} \mathrm{~S}_{01}$ & \multirow{3}{*}{$\begin{array}{c}\text { Munshiganj, Munshiganj Sadar } \\
\text { (Field) }\end{array}$} & \multirow{3}{*}{ Solanum tuberosum } & +ve & $+\mathrm{ve}$ & $+\mathrm{ve}$ \\
\hline $\mathrm{P}_{1} \mathrm{MMuF}_{14} \mathrm{~S}_{02}$ & & & $+\mathrm{ve}$ & $+\mathrm{ve}$ & $+\mathrm{ve}$ \\
\hline $\mathrm{P}_{1} \mathrm{MMuF}_{17} \mathrm{~S}_{03}$ & & & +ve & $-\mathrm{ve}$ & - \\
\hline
\end{tabular}




\section{Continued}

\begin{tabular}{|c|c|c|c|c|c|}
\hline $\mathrm{P}_{1} \mathrm{MSiF}_{33} \mathrm{~S}_{04}$ & & & +ve & + ve & +ve \\
\hline $\mathrm{P}_{1} \mathrm{MSiF}_{35} \mathrm{~S}_{05}$ & Munshiganj, Sirajdikhan (Field) & Solanum tuberosum & $+\mathrm{ve}$ & + ve & $+\mathrm{ve}$ \\
\hline $\mathrm{P}_{1} \mathrm{MSiF}_{39} \mathrm{~S}_{06}$ & & & +ve & + ve & $-\mathrm{ve}$ \\
\hline $\mathrm{P}_{1} \mathrm{MTF}_{9} \mathrm{~S}_{07}$ & & & $-\mathrm{ve}$ & $-\mathrm{ve}$ & $-\mathrm{ve}$ \\
\hline $\mathrm{P}_{1} \mathrm{MTF}_{20} \mathrm{~S}_{08}$ & Munshiganj, Tongibari (Field) & Solanum tuberosum & $+\mathrm{ve}$ & $+\mathrm{ve}$ & $+\mathrm{ve}$ \\
\hline $\mathrm{P}_{1} \mathrm{MTF}_{29} \mathrm{~S}_{09}$ & & & +ve & $+\mathrm{ve}$ & $-\mathrm{ve}$ \\
\hline $\mathrm{P}_{1} \mathrm{~N}_{\mathrm{il}} \mathrm{DF}_{11} \mathrm{~S}_{10}$ & & & $+\mathrm{ve}$ & + ve & $+\mathrm{ve}$ \\
\hline $\mathrm{P}_{1} \mathrm{~N}_{\mathrm{il}} \mathrm{DF}_{21} \mathrm{~S}_{11}$ & Nilphamari, Domar (Field) & Solanum tuberosum & $-\mathrm{ve}$ & $-\mathrm{ve}$ & - \\
\hline $\mathrm{P}_{1} \mathrm{~N}_{\mathrm{il}} \mathrm{DF}_{23} \mathrm{~S}_{12}$ & & & $+\mathrm{ve}$ & + ve & + ve \\
\hline $\mathrm{P}_{1} \mathrm{~N}_{\mathrm{il}} \mathrm{NiF}_{19} \mathrm{~S}_{13}$ & & & $+\mathrm{ve}$ & $+\mathrm{ve}$ & $+\mathrm{ve}$ \\
\hline $\mathrm{P}_{1} \mathrm{~N}_{\mathrm{il}} \mathrm{NiF}_{21} \mathrm{~S}_{14}$ & $\begin{array}{l}\text { Nilphamari, Nilphamari Sadar } \\
\text { (Field) }\end{array}$ & Solanum tuberosum & -ve & -ve & - \\
\hline $\mathrm{P}_{1} \mathrm{~N}_{\mathrm{il}} \mathrm{NiF}_{31} \mathrm{~S}_{15}$ & & & +ve & $+\mathrm{ve}$ & + ve \\
\hline $\mathrm{P}_{1} \mathrm{~N}_{\mathrm{il}} \mathrm{DiF}_{7} \mathrm{~S}_{16}$ & & & $+\mathrm{ve}$ & $+\mathrm{ve}$ & $-\mathrm{ve}$ \\
\hline $\mathrm{P}_{1} \mathrm{~N}_{\mathrm{il}} \mathrm{DiF}_{17} \mathrm{~S}_{17}$ & Nilphamari, Dimla (Field) & Solanum tuberosum & -ve & $-\mathrm{ve}$ & - \\
\hline $\mathrm{P}_{1} \mathrm{~N}_{\mathrm{il}} \mathrm{DiF}_{25} \mathrm{~S}_{18}$ & & & $+\mathrm{ve}$ & $+\mathrm{ve}$ & $+\mathrm{ve}$ \\
\hline $\mathrm{P}_{1} \mathrm{NNaF}_{3} \mathrm{~S}_{19}$ & & & $+\mathrm{ve}$ & + ve & + ve \\
\hline $\mathrm{P}_{1} \mathrm{NNaF}_{13} \mathrm{~S}_{20}$ & $\begin{array}{c}\text { Narayangonj, Narayangonj Sadar } \\
\text { (Field) }\end{array}$ & Solanum tuberosum & -ve & -ve & - \\
\hline $\mathrm{P}_{1} \mathrm{NNaF}_{30} \mathrm{~S}_{21}$ & & & +ve & + ve & + ve \\
\hline $\mathrm{P}_{1} \mathrm{NSF}_{4} \mathrm{~S}_{22}$ & & & +ve & $+\mathrm{ve}$ & + ve \\
\hline $\mathrm{P}_{1} \mathrm{NSF}_{14} \mathrm{~S}_{23}$ & Narayangonj, Sonargaon (Field) & Solanum tuberosum & -ve & -ve & - \\
\hline $\mathrm{P}_{1} \mathrm{NSF}_{25} \mathrm{~S}_{24}$ & & & +ve & + ve & $+\mathrm{ve}$ \\
\hline $\mathrm{P}_{1} \mathrm{NRuF}_{3} \mathrm{~S}_{25}$ & & & +ve & + ve & $+\mathrm{ve}$ \\
\hline $\mathrm{P}_{1} \mathrm{NRuF}_{13} \mathrm{~S}_{26}$ & Narayangonj, Rupgonj (Field) & Solanum tuberosum & $-\mathrm{ve}$ & $-\mathrm{ve}$ & - \\
\hline $\mathrm{P}_{1} \mathrm{NRuF}_{22} \mathrm{~S}_{27}$ & & & +ve & + ve & + ve \\
\hline $\mathrm{CNRF}_{14} \mathrm{~S}_{01}$ & & & -ve & -ve & - \\
\hline $\mathrm{CNRF}_{21} \mathrm{~S}_{02}$ & Narayangonj, Rupgonj (Field) & Capsicum annum & $-\mathrm{ve}$ & $-\mathrm{ve}$ & - \\
\hline $\mathrm{CNRF}_{41} \mathrm{~S}_{03}$ & & & -ve & -ve & - \\
\hline SoMMuF $_{1} \mathrm{~S}_{01}$ & & & $+\mathrm{ve}$ & + ve & $+\mathrm{ve}$ \\
\hline SoM MuF $\mathrm{S}_{02}$ & $\begin{array}{l}\text { Munshiganj, Munshiganj Sadar } \\
\text { (Field) }\end{array}$ & Soil & $+\mathrm{ve}$ & + ve & $+\mathrm{ve}$ \\
\hline SoM $\mathrm{MuF}_{3} \mathrm{~S}_{03}$ & & & +ve & -ve & - \\
\hline SoMSiF $_{1} \mathrm{~S}_{04}$ & & & $+\mathrm{ve}$ & $+\mathrm{ve}$ & +ve \\
\hline $\mathrm{SoMSiF}_{2} \mathrm{~S}_{05}$ & Munshiganj, Sirajdikhan (Field) & Soil & $+\mathrm{ve}$ & $+\mathrm{ve}$ & + ve \\
\hline $\mathrm{SoMSiF}_{3} \mathrm{~S}_{06}$ & & & $+\mathrm{ve}$ & $-\mathrm{ve}$ & - \\
\hline SoMToF $_{1} \mathrm{~S}_{07}$ & & & $+\mathrm{ve}$ & $+\mathrm{ve}$ & $+\mathrm{ve}$ \\
\hline $\mathrm{SoMToF}_{2} \mathrm{~S}_{08}$ & Munshiganj, Tongibari (Field) & Soil & -ve & -ve & - \\
\hline SoMToF $_{21} \mathrm{~S}_{09}$ & & & -ve & -ve & - \\
\hline SoMToF $_{30} \mathrm{~S}_{10}$ & & & +ve & $+\mathrm{ve}$ & + ve \\
\hline
\end{tabular}




\section{Continued}

\begin{tabular}{|c|c|c|c|c|c|}
\hline $\mathrm{SoN}_{\mathrm{il}} \mathrm{DF}_{1} \mathrm{~S}_{11}$ & & & $+\mathrm{ve}$ & $+\mathrm{ve}$ & -ve \\
\hline $\mathrm{SoN}_{\mathrm{il}} \mathrm{DF}_{2} \mathrm{~S}_{12}$ & Nilphamari, Domar (Field) & Soil & $+\mathrm{ve}$ & $+\mathrm{ve}$ & -ve \\
\hline $\mathrm{SoN}_{\mathrm{il}} \mathrm{DF}_{3} \mathrm{~S}_{13}$ & & & +ve & $+\mathrm{ve}$ & +ve \\
\hline $\mathrm{SoN}_{\mathrm{il}} \mathrm{NiF}_{1} \mathrm{~S}_{14}$ & & & +ve & $+\mathrm{ve}$ & +ve \\
\hline $\mathrm{SoN}_{\mathrm{il}} \mathrm{NiF}_{2} \mathrm{~S}_{15}$ & $\begin{array}{l}\text { Nilphamari, Nilphamari Sadar } \\
\text { (Field) }\end{array}$ & Soil & $-\mathrm{ve}$ & $-\mathrm{ve}$ & - \\
\hline $\mathrm{SoN}_{\mathrm{il}} \mathrm{NiF}_{3} \mathrm{~S}_{16}$ & & & +ve & $+\mathrm{ve}$ & +ve \\
\hline $\mathrm{SoN}_{\mathrm{il}} \mathrm{DiF}_{1} \mathrm{~S}_{17}$ & & & $+\mathrm{ve}$ & $+\mathrm{ve}$ & -ve \\
\hline $\mathrm{SoN}_{\mathrm{il}} \mathrm{DiF}_{2} \mathrm{~S}_{18}$ & Nilphamari, Dimla (Field) & Soil & $+\mathrm{ve}$ & $+\mathrm{ve}$ & $+\mathrm{ve}$ \\
\hline $\mathrm{SoN}_{\mathrm{il}} \mathrm{DiF}_{3} \mathrm{~S}_{19}$ & & & -ve & $-\mathrm{ve}$ & - \\
\hline $\mathrm{SoNNaF}_{1} \mathrm{~S}_{20}$ & & & $+\mathrm{ve}$ & $+\mathrm{ve}$ & $+\mathrm{ve}$ \\
\hline $\mathrm{SoNNaF}_{2} \mathrm{~S}_{21}$ & $\begin{array}{c}\text { Narayangonj, Narayangonj Sadar } \\
\text { (Field) }\end{array}$ & Soil & +ve & $+\mathrm{ve}$ & -ve \\
\hline $\mathrm{SoNNaF}_{3} \mathrm{~S}_{22}$ & & & $+\mathrm{ve}$ & $+\mathrm{ve}$ & $-\mathrm{ve}$ \\
\hline $\operatorname{SoNSF}_{1} \mathrm{~S}_{23}$ & & & $+\mathrm{ve}$ & $+\mathrm{ve}$ & $+\mathrm{ve}$ \\
\hline $\mathrm{SoNSF}_{2} \mathrm{~S}_{24}$ & Narayangonj, Sonargaon (Field) & Soil & $+\mathrm{ve}$ & $+\mathrm{ve}$ & -ve \\
\hline $\mathrm{SoNSF}_{3} \mathrm{~S}_{25}$ & & & $+\mathrm{ve}$ & $+\mathrm{ve}$ & $+\mathrm{ve}$ \\
\hline $\operatorname{SoNRuF}_{1} \mathrm{~S}_{26}$ & & & -ve & $-\mathrm{ve}$ & - \\
\hline $\mathrm{SoNRuF}_{2} \mathrm{~S}_{27}$ & Narayangonj, Rupgonj (Field) & Soil & $+\mathrm{ve}$ & $+\mathrm{ve}$ & $+\mathrm{ve}$ \\
\hline $\mathrm{SoNRuF}_{3} \mathrm{~S}_{28}$ & & & $+\mathrm{ve}$ & $+\mathrm{ve}$ & -ve \\
\hline $\mathrm{WMSiF}_{13} \mathrm{~S}_{01}$ & Munshigonj, Sirajdikhan (Field) & & $+\mathrm{ve}$ & + ve & -ve \\
\hline $\mathrm{WMSiF}_{33} \mathrm{~S}_{02}$ & & & $+\mathrm{ve}$ & $+\mathrm{ve}$ & $-\mathrm{ve}$ \\
\hline $\mathrm{WN}_{\mathrm{il}} \mathrm{NiF}_{16} \mathrm{~S}_{03}$ & Nilphamari, Nilphamari Sadar & Cynodon dactylon & $-\mathrm{ve}$ & $-\mathrm{ve}$ & - \\
\hline $\mathrm{WN}_{\mathrm{il}} \mathrm{NiF}_{23} \mathrm{~S}_{04}$ & (Field) & & -ve & $-\mathrm{ve}$ & - \\
\hline $\mathrm{WNRuF}_{36} \mathrm{~S}_{05}$ & Narayangonj, Rupgonj (Field) & & $+\mathrm{ve}$ & $+\mathrm{ve}$ & -ve \\
\hline $\mathrm{BNRF}_{2} \mathrm{~S}_{01}$ & & & $+\mathrm{ve}$ & $+\mathrm{ve}$ & -ve \\
\hline $\mathrm{BNRF}_{13} \mathrm{~S}_{02}$ & Narayangonj, Rupgonj (Field) & Musa spp & -ve & -ve & - \\
\hline $\mathrm{BNRF}_{22} \mathrm{~S}_{03}$ & & & +ve & $+\mathrm{ve}$ & -ve \\
\hline $\mathrm{WaMSiF}_{1} \mathrm{~S}_{01}$ & & & -ve & -ve & - \\
\hline $\mathrm{WaMSiF}_{12} \mathrm{~S}_{02}$ & $\begin{array}{c}\text { Munshigonj, Sirajdikhan (Irrigation } \\
\text { Water-Field) }\end{array}$ & Water & +ve & $+\mathrm{ve}$ & +ve \\
\hline $\mathrm{WaMSiF}_{30} \mathrm{~S}_{03}$ & & & $+\mathrm{ve}$ & $+\mathrm{ve}$ & -ve \\
\hline $\mathrm{WaN}_{\mathrm{il}} \mathrm{NiF}_{11} \mathrm{~S}_{04}$ & & & $+\mathrm{ve}$ & $+\mathrm{ve}$ & -ve \\
\hline $\mathrm{WaRNiF}_{23} \mathrm{~S}_{05}$ & $\begin{array}{l}\text { Nilphamari, Nilphamery Sadar } \\
\text { (Irrigation Water-Field) }\end{array}$ & Water & $+\mathrm{ve}$ & $+\mathrm{ve}$ & -ve \\
\hline $\mathrm{WaRNiF}_{34} \mathrm{~S}_{06}$ & & & -ve & $-\mathrm{ve}$ & - \\
\hline $\mathrm{WaNRuF}_{1} \mathrm{~S}_{07}$ & & & -ve & $-\mathrm{ve}$ & - \\
\hline $\mathrm{WaNRuF}_{2} \mathrm{~S}_{08}$ & $\begin{array}{c}\text { Narayangonj, Rupgonj (Irrigation } \\
\text { Water-Field) }\end{array}$ & Water & +ve & $+\mathrm{ve}$ & -ve \\
\hline $\mathrm{WaNRuF}_{3} \mathrm{~S}_{09}$ & & & $+\mathrm{ve}$ & $+\mathrm{ve}$ & -ve \\
\hline
\end{tabular}


Finally, one hundred and thirty isolates of $R$. solanacearum were isolated from potato tuber, potato stems, chili stems, banana leaves, weed, soil and irrigation water. Above them one hundred and six isolates were positive on TZC solid medium. Fluidal pinkish red centered colonies, typical of $R$. solanacearum were observed on TZC solid medium. Among them ninety isolates were virulent and sixteen isolates were avirulent (Table 3 and Plate 1). All virulent isolates were
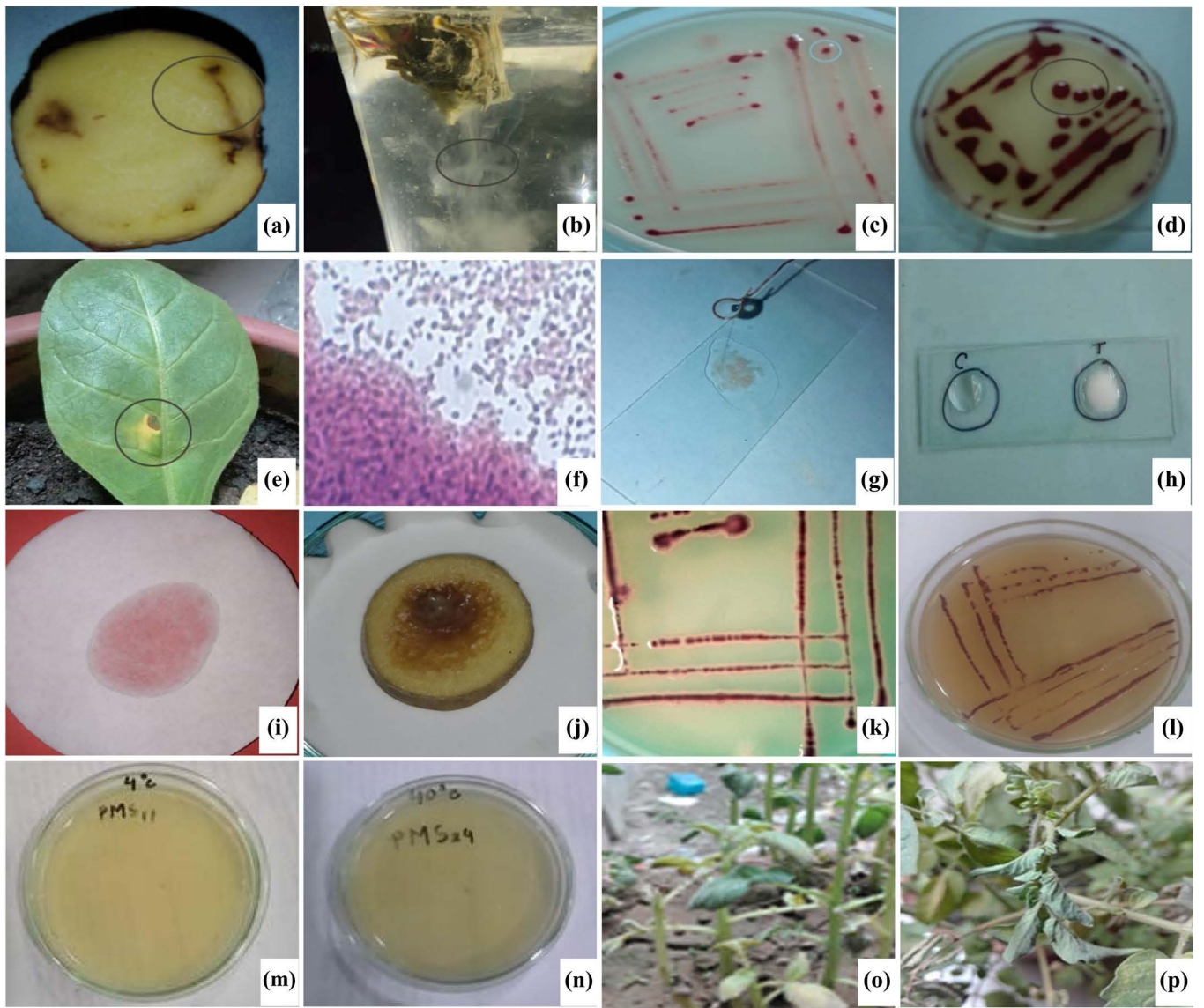

(g)

(h)

(j)
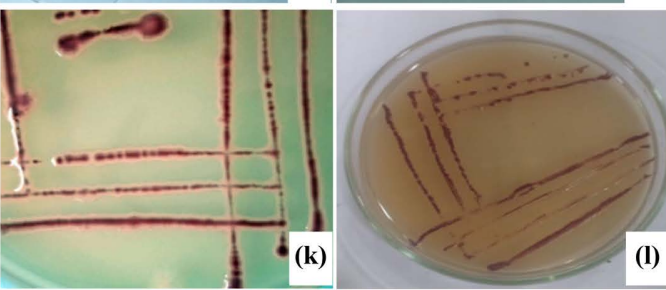

(m)
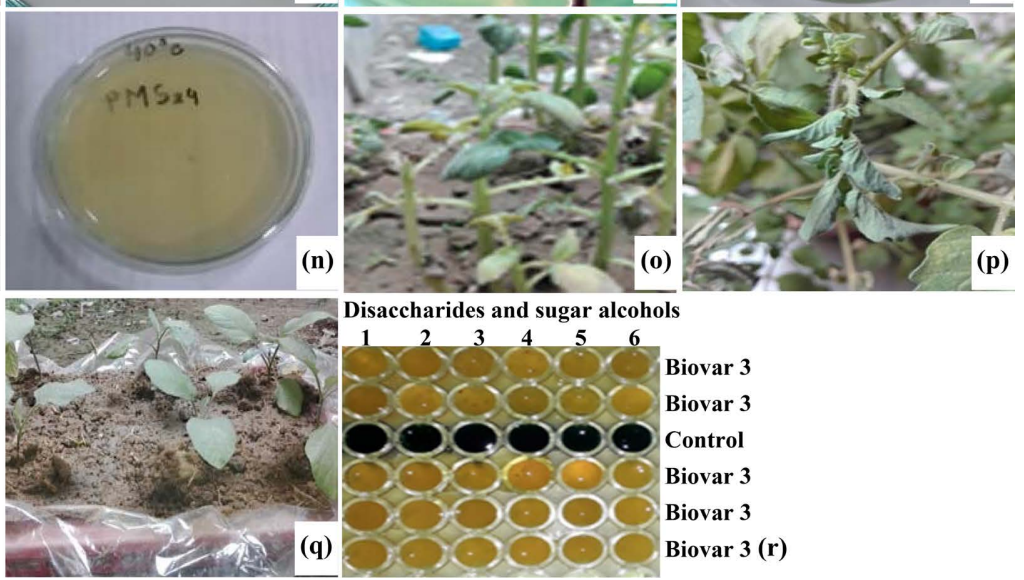

Disaccharides and sugar alcohols

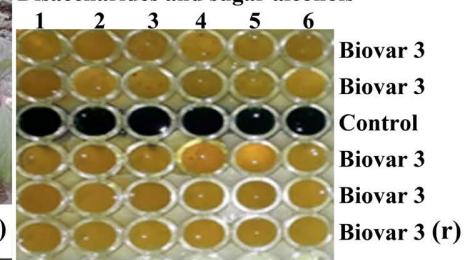

Plate 1. (a) Brown discoloration of vascular tissue; (b) Bacterial ooze from cut stem; (c) Virulent colonies on TZC medium; (d) Avirulent colonies on TZC medium (uniformly round and dark red); (e) Death cell showed on $R$. solanacearum inoculated leaf of tobacco due to hypersensitive reaction; (f) Gram staining test; (g) Catalase test; (h) KOH test; (i) Kovacs oxidase test; (j) Pectolytic test; (k) $R$. solanacearum at $28^{\circ} \mathrm{C}$ (Typical growth); (l) $R$. solanacearum at $37^{\circ} \mathrm{C}$ (Typical growth); (m) No potential growth of $R$. solanacearum at $4^{\circ} \mathrm{C}$; (n) No potential growth of $R$. solanacearum at $40^{\circ} \mathrm{C}$; (o) Pathogenicity test positive on potato seedlings after artificial inoculation of $R$. solanacearum; (p) Pathogenicity test positive on tomato seedlings after artificial inoculation of $R$. solanacearum; (q) Pathogenicity test negetive on brinjal seedlings after artificial inoculation of $R$. solanacearum and (r) biovar (s); (s) test of $R$. solanacearum showing a positive result (yellow colour) and a negative result (green colour) $(1=$ Cellobiose: 2 = Lactose; $3=$ Maltose; 4 = Dulcitol; 5 = Mannitol; 6 = Sorbitol). 
tested for hypersensitive response on tobacco plants (Table 3 and Plate 1). Depending upon the appearance of hypersensitive reaction, fifty-seven isolates producing symptoms within 2 - 5 days after bacterial inoculation on tobacco leaves. On the basis of all tests performed which were positive for hypersensative reaction. Fifty isolates out of fifty-seven isolates showed positive reaction in gram staining test, $\mathrm{KOH}$ test, catalase test, kovac's oxidase test and pectolytic test (Table 5 and Plate 1). In temperature sensitivity test, the test isolates showed positive and typical growth at $28^{\circ} \mathrm{C}$ and $37^{\circ} \mathrm{C}$ but did not show any potential growth at $4^{\circ} \mathrm{C}$ and $40^{\circ} \mathrm{C}$ (Table 5 and Plate 1 ).

Among fifty isolates, nine isolates selected from three districts produced the bands of 280 bp size (Table 4 and Figure 1) specific for $R$. solanacearum with species specific primers which mean that, those isolate(s) were belonged to $R$. solanacearum.

In race determination test fifty isolates showed wilting symptoms on potato and tomato seedlings except brinjal seedlings (Table 5 and Plate 1). Fifty isolates were expressed as race 3. Forty-eight isolates were expressed as biovar III after 7 - 8 days and the remaining two isolates from soil and water were expressed as biovar I on the basis of utilization of different sugars (Table 5 and Plate 1).

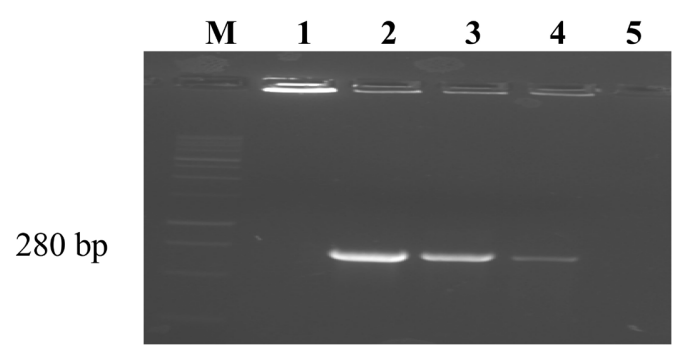

Figure 1. Gel electrophoresis of amplified 280 bp DNA fragments from $R$. solanacearum with species specific primers. $\mathrm{M}=100 \mathrm{bp}$ DNA ladder, $1=$ negative control, 2 to $4=$ representative three strains of $R$. solanacearum from three districts and $5=$ blank control.

Table 4. PCR based identification of Ralstonia solanacearum collected from three districts of Bangladesh.

\begin{tabular}{cccccc}
\hline \multicolumn{1}{c}{ Isolates } & Locations of sampling & Districts & Source of infection & Band size & Inference \\
\hline $\mathrm{PM} \mathrm{MuTa}_{5} \mathrm{CS}_{01}$ & Munshiganj Sadar (Tamanna Cold Storage) & & Solanum tuberosum & $280 \mathrm{bp}$ & $R$. solanacearum \\
$\mathrm{PM} \mathrm{MuFa}_{15} \mathrm{~S}_{07}$ & Munshiganj Sadar (Farmer Storage) & Munshigonj & Solanum tuberosum & $280 \mathrm{bp}$ & $R$. solanacearum \\
$\mathrm{PlMSiF}_{33} \mathrm{~S}_{04}$ & Sirajdikhan (Field) & & Solanum tuberosum & $280 \mathrm{bp}$ & $R$. solanacearum \\
$\mathrm{PNSSa}_{9} \mathrm{CS}_{46}$ & Sonargaon (Sahin Cold Storage) & & Solanum tuberosum & $280 \mathrm{bp}$ & $R$. solanacearum \\
$\mathrm{PNSFa}_{20} \mathrm{~S}_{48}$ & Sonargaon (Farmer Storage) & Narayangonj & Solanum tuberosum & $280 \mathrm{bp}$ & $R$. solanacearum \\
$\mathrm{P}_{1} \mathrm{NNaF}_{3} \mathrm{~S}_{19}$ & Narayangonj sadar (Field) & & Solanum tuberosum & $280 \mathrm{bp}$ & $R$. solanacearum \\
$\mathrm{PN}_{\mathrm{il}} \mathrm{DSh}_{46} \mathrm{CS}_{25}$ & Domar (Shawon Cold Storage) & & Solanum tuberosum & $280 \mathrm{bp}$ & $R$. solanacearum \\
$\mathrm{P}_{1} \mathrm{~N}_{\mathrm{il}} \mathrm{DiFa}_{25} \mathrm{~S}_{18}$ & Dimla (Farmer) & Nilphamari & Solanum tuberosum & $280 \mathrm{bp}$ & $R$. solanacearum \\
$\mathrm{P}_{1} \mathrm{~N}_{\mathrm{il}} \mathrm{DF}_{11} \mathrm{~S}_{10}$ & Domar (Field) & & Solanum tuberosum & $280 \mathrm{bp}$ & $R$. solanacearum \\
\hline
\end{tabular}


Table 5. Result of different biochemical test, race determinationand biovar test for characterization of different isolates of $R$. solanacearum collected from different locations of Bangladesh.

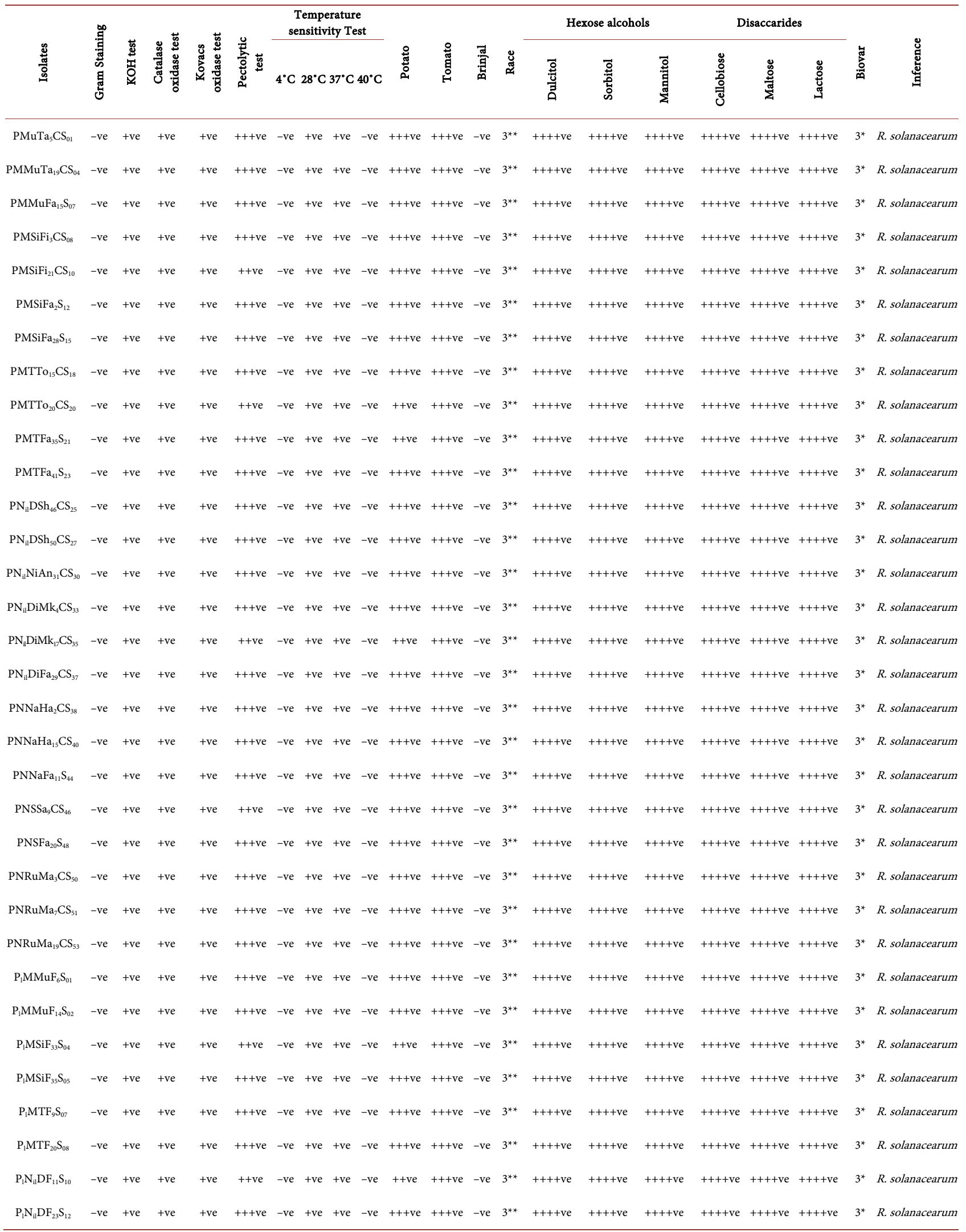




\section{Continued}

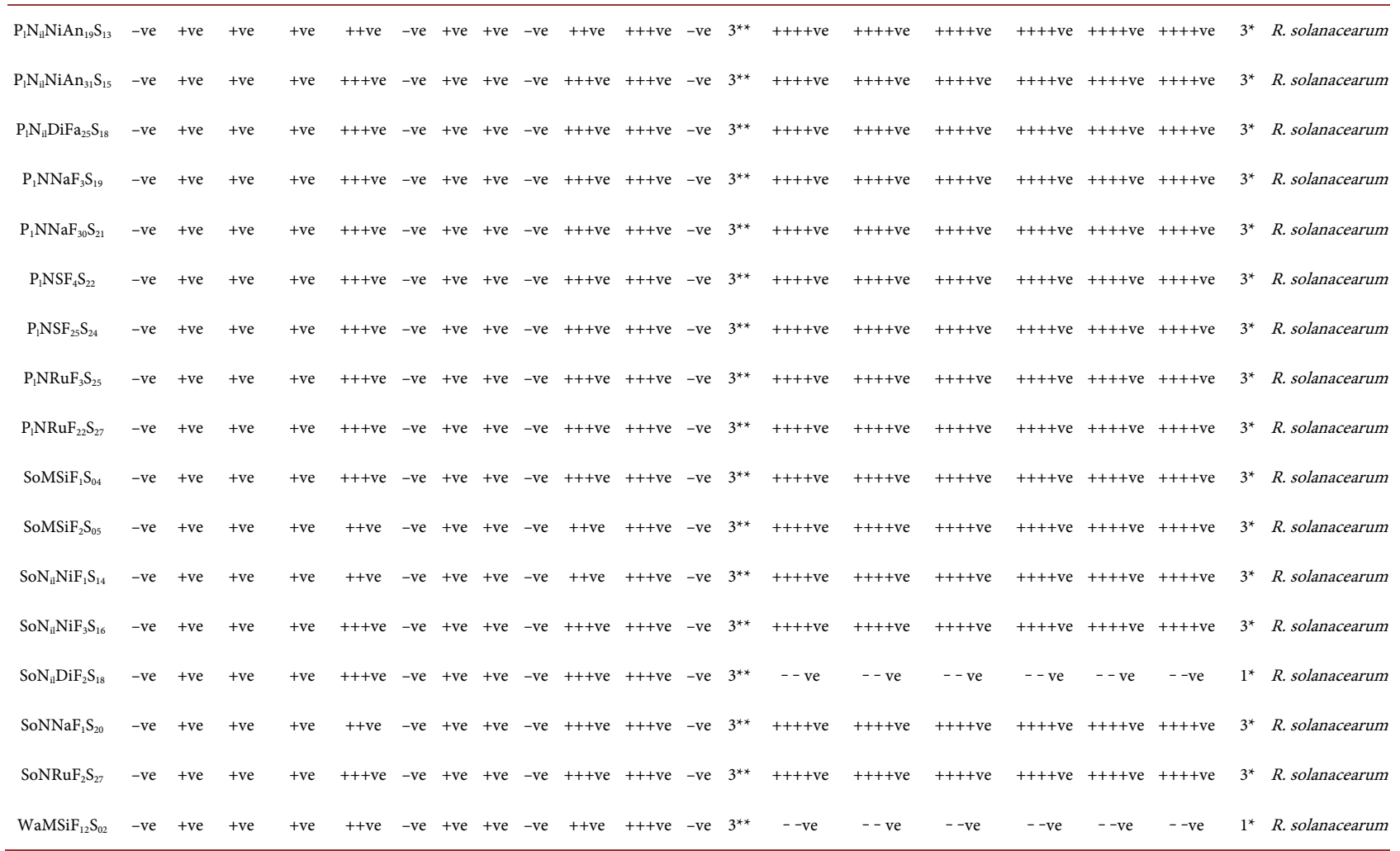

“+ve" means positive reaction; “-ve" means negative reaction; “+++ve" means strongly positive reaction; and "++ve” means weakly positive reaction; "++++ve" means positive reaction (Yellow color produced due to change in $\mathrm{pH}$ ); “--ve" means negative reaction (Green color remained as $\mathrm{pH}$ did not change); $3^{* *}=$ Race $3 ; 3^{*}=$ Biovar III; $1^{*}=$ Biovar 1 .

\section{Discussion}

Samples were collected from different sources viz. potato tuber, potato stem, chili stem, banana leaves, soil, weeds and irrigation water from major potato growing nine upazila under three districts of Bangladesh. Potato samples were collected from field, farmer storage and cold storage and other samples were collected from positive location under streaming and oozing test to investigate the presence of $R$. solanacearum. The causal agent (Ralstonia solanacearum) isolated from infected organism which has been described all around the world, tuber [36] [42], plant [15] [36] [42], soil [37] [43], banana [2], asymptomatic weeds [44] [45], chilli [46] and water [15] [47]. In potato tuber, no oozing was found but browning of the vascular bundle region of seed tuber were observed. Cross cut of plant samples showed bacterial ooze streaming in clear water. Cutting a diseased tuber will reveal browning and necrosis of the vascular ring and in adjacent tissues. A creamy fluid exudate usually appears spontaneously from the vascular ring at the cut surface. Bacterial ooze can emerge from the eyes and stem-end attachment of whole tubers, to which soil adheres. If cut stem or tuber vascular tissue is placed in water, threads of bacterial ooze exude [13].

TZC medium [23] is widely used and best studied media to characterize $R$. solanacearum. Virulent isolates showed the typical colony characters which are 
mucous and pink-centered on TZC solid media and smooth margins are normally avirulent [24] [29] [30]. A total of one hundred thirty samples were used for isolation on TZC solid medium out of which $94 \%$ (i.e. 106) found positive for $R$. solanacearum presence.

Among the isolates fifty-seven isolates were able to cause rapid death of local cell of tissue between veins of tobacco leaves. $R$. solanacearum was able to produce HR in tobacco leaves. These results clearly indicated that like other plant pathogenic bacteria, $R$. solanacearum isolates possess Hrp type III secretion system which is responsible for inducing HR on tobacco leaves [28].

Incase of biochemical tests, fifty isolates showed positive gram reaction, $\mathrm{KOH}$ reaction, catalase, kovac'soxidase and pectolytic tests and showed similar reaction to temperature sensitivity test. So, isolates of $R$. solanacearum were gram negative and straight or curved rod shaped which is the characteristic feature of any plant pathogenic bacteria [29]. Gram negative bacteria have fragile cell walls which are bounded by an outer membrane that is why gram negative bacteria produce slime threads in a $3 \% \mathrm{KOH}$. Those slime threads were actually DNA. That is why this test is also called lytic release of DNA. But Gram-positive bacteria by contrast possess a thicker, more rigid cell wall which resists the disruptive effect of $\mathrm{KOH}$ [30]. Entire gram-negative bacteria produce gas bubbles when these were mixed with a drop of $3 \% \mathrm{H}_{2} \mathrm{O}_{2}$ on glass slide. Production of gas bubbles gives a clue for presence of aerobic and facultative bacteria [29]. Kovacs oxidase test was used for differentiation between aerobic and anaerobic bacteria [48]. Fifty Isolates of $R$. solanacearum produced dark purple color within 10 - 60 seconds. It indicates those isolates were aerobic bacteria [25] [49]. Pectolytic test was physiological test. In pectolytic test, fifty isolates of $R$. solanacearum showed positive reaction producing soft rot in inoculated potatoes [25] [29] [32] [50]. In temperature sensitivity test all test isolates showed positive and typical growth at $28^{\circ} \mathrm{C}$ and $37^{\circ} \mathrm{C}$ but did not show any potential growth at $4^{\circ} \mathrm{C}$ and $40^{\circ} \mathrm{C}$. R. solanacearum growth on TZC media at $28^{\circ} \mathrm{C}$ and $37^{\circ} \mathrm{C}$ not growth at $41^{\circ} \mathrm{C}$ [51]. $R$. solanacearum is able to survive even in colder environments for about 3 years and it is severe in temperature ranges of $24^{\circ} \mathrm{C}-35^{\circ} \mathrm{C}$ with optimum of $27^{\circ} \mathrm{C}$ [52]. Nine isolates out of three districts produced the bands $280 \mathrm{bp}$ specific for $R$. solanacearum. Many scientists in world wide also used 759/760 primers for detecting the $R$. solanacearum in potato [53] [54] [55].

Fifty isolates showed wilting symptoms on potato and tomato seedlings except brinjal seedlings except some chlorosis on leaves. At last wilting and collapse of whole plants can lead to rapid death. When the cut end of infected stem kept in a glass of water the milky or cloudy threads like streaming signifies the presence of $R$. solanacearum [19] [56]. So, it was observed that all (fifty) tested isolates expressed as race 3 . However, in the present study race 1 , race 2 , race 4 and race 5 were not detected since race 1 is infect all solanaceous and a wide range of plants (solanaceous and nonsolanaceous weeds, diploid bananas, groundnut, olive, ginger, straw berry, geranium, eucalyptus, some other plants) which were 
available in Asia, Australia and America while race 3 infects only potato and tomato worldwide [36], race 2 is restricted to triploid banana and heliconia; race 4 infects ginger; and race 5 is pathogenic on mulberry [40] [57] [58].

In case of biovar test, forty eight out of fifty isolates of $R$. solanacearum had shown to oxidize the different carbon sources from both disaccharides and sugar alcohols and changed the green color of the medium into yellow which was indicating the oxidation of both carbons so expressing those as biovar III. But, the remaining two isolates from soil and water neither changed the color for disaccharides nor for sugar alcohols which meant that those were not able to utilize either of the carbon sources and they were biovar I. $R$. solanacearum has been grouped into five biovars on the basis of utilizing or oxidizing three hexoses (mannitol, dulcitol and sorbitol) and three disaccharides (lactose, maltose and cellobiose) [31] [35]. Biovar I oxidize none of disaccharide sugar and hexose alcohol, biovar II oxidizes only disaccharide sugars, Biovar III oxidizes both of disaccharide sugars and hexose alcohols, biovar IV oxidizes only hexose alcohols whereas biovar $\mathrm{V}$ disaccharide sugar and oxidizes only mannitol hexose alcohol not sorbito and dulcitol [31] [35]. Bangladeshi $R$. solanacearum isolates of potato belonging to race 3 biovar III [17] [18]. It is clearly revealed that all groups of $R$. solanacearum isolates oxidized disaccharides (sucrose, lactose, and maltose) and sugar alcohols (manitol, sorbitol and dulcitol) within 3 - 5 days and confirmed biovar as III.

\section{Conclusions}

Among 106 collected isolates from different sources, $81.54 \%$ isolates showed positive reaction on TZC test, 50 isolates showed race 3; biovar III except one from each of Munshigonj and Nilphamari which showed as biovar I; and nine isolates out of three districts showed 280 bp DNA fragment amplification through the species-specific primer of Bangladeshi isolates.

The most prevalent and frequent isolate, race 3 biovar III were observed in Bangladesh at Munshigonj, Narayangonj and Nilphamari districts that are major potato growing areas and sources of seed potatoes for all over Bangladesh. It is urgently important to confirm the presence of the most disastrous $R$. solanaceaum isolate, race 3 biovar III isolates in other regions and prevent further spread to other hosts or regions of Bangladesh.

\section{Acknowledgements}

Authors thank to the anonymous reviewers for their kind review of the manuscript. The research work was financially supported by the grant of BAS-USDA-PALS-CR 10 .

\section{Conflicts of Interest}

The authors declare no conflicts of interest regarding the publication of this paper. 


\section{References}

[1] Smith, E.F. (1896) A Bacterial Disease of the Tomato, Eggplant, and Irish Potato (Bacillus solanacearum nov. sp.). Bulletin No. 12, US Department of Agriculture, Division of Vegetable Physiology and Pathology, Washington DC, 1-28.

[2] Yabuuchi, E., Kosako, Y., Yano, I., Hotta, H. and Nishiuchi, Y. (1995) Transfer of Two Burkholderia and an Alcaligenes Species to Ralstonia Gen. Nov. Microbiology and Immunology, 39, 897-904. https://doi.org/10.1111/j.1348-0421.1995.tb03275.x

[3] DAE (Department of Agriculture Extension) (2015) Agricultural Statistics. Ministry of Agriculture, Kharmarbari, Farmgate, Dhaka.

[4] Taiwo, L.B., Adebayo, D.T., Adebayo, O.S. and Adediran, J.A. (2007) Compost and Glomus mosseae on Management of Bacterial and Fusarium Wilts of Tomato. International Journal of Vegetable Science, 13, 49-61. https://doi.org/10.1300/J512v13n02_05

[5] Yuliar, Nion, Y.A. and Toyota, K. (2015) Recent Trends in Control Methods for Bacterial Wilt Diseases Caused by Ralstonia solanacearum. Microbes and Environments, 30, 1-11. https://doi.org/10.1264/jsme2.ME14144 https://www.jstage.jst.go.jp/browse/jsm

[6] Safni, I., Cleenwerck, I., De, Vos, P., Fegan, M., Sly, L. and Kappler, U. (2014) Polyphasic Taxonomic Revision of the Ralstonia solanacearum Species Complex: Proposal to Emend the Descriptions of Ralstonia solanacearum and Ralstonia syzygii and Reclassify Current $R$. syzygii Strains as Ralstonia syzygii Subsp. Syzygii Subsp. November, $R$. solanacearum Phylotype IV Strains as Ralstonia syzygii Subsp. Indonesiensis Subsp. November, Banana Blood Disease Bacterium Strains as Ralstonia syzygii Subsp. Celebesensis Subsp. November and $R$. solanacearum Phylotype I and III Strains as Ralstonia pseudosolanacearum sp. Nov. International Journal of Systematicand Evolutionary Microbiology, 64, 3087-3103.

https://doi.org/10.1099/ijs.0.066712-0

[7] Denny, T.P. (2006) Plant Pathogenic Rastonia Species. In: Gnanamanickam, S.S., Ed., Plant-Associated Bacterial, Springer Publishing, Dordrecht, 573-644. https://doi.org/10.1007/978-1-4020-4538-7_16

[8] Hayward, A.C. (1991) Biology and Epidemiology of Bacterial Wilt Caused by Pseudomonas solanacearum. Annual Review of Phytopathology, 29, 65-87. https://doi.org/10.1146/annurev.py.29.090191.000433

[9] CABI (Center for Agriculture and Bioscience International) (2017) Phytophthora Infestans (Phytophthora Blight). https://www.cabi.org/isc/datasheet/40970

[10] Champoiseau, P.G., Jones, J.B. and Allen, C. (2009) Ralstonia solanacearum Race 3 Biovar 2 Causes Tropical Losses and Temperate Anxieties. Plant Health Progress, 10, 1-10. https://doi.org/10.1094/PHP-2009-0313-01-RV

[11] Johnson, S.B. (2003) Bacterial wilt. Spudlines, 41, 1.

[12] Lemay, A., Redlin, S., Fowler, G. and Dirani, M. (2003) Pest Dana Sheet: Ralstonia Solanacearum Race 3 Biovar 2.

https://plantpath.ifas.ufl.edu/rsol/RalstoniaPublications_PDF/USDARalstoniaPestD ataSheet_2003.pdf

[13] Charkowski, A., Sharma, K., Parker, M.L., Secor, G.A. and Elphinstone, J. (2020) Chapter 10: Bacterial Diseases of Potato. In: Campos, H. and Ortiz, O., Eds., The Potato Crop: Its Agricultural, Nutritional and Social Contribution to Humankind, Springer, Cham, 351-388. https://doi.org/10.1007/978-3-030-28683-5_10

[14] Champoiseau, G. (2008) Ralstonia Solanacearum Race 3 Biovar 2: Detection, Exclu- 
sion and Analysis of a Select Agent Educational Modules. The United States Department of Agriculture, National Research Initiative Program (2007-2010), pp. $1-17$.

https://plantpath.ifas.ufl.edu/rsol/RalstoniaPublications_PDF/RsolanacearumR3b2_ PDF.pdf.

[15] Sullivan, M., Daniells, E., Southwick, C. and Mackesy, D. (2013) CPHST (Center for Plant Health Science and Technology) Pest Datasheet for Ralstonia solanacearum Race 3 Biovar 2. USDA-APHIS-PPQ-Center for Plant Health Science and Technology Plant Epidemiology and Risk Analysis Laboratory, Raleigh.

[16] Pest Risk Analysis (2015) Pest Risk Analysis (PRA) of Potato in Bangladesh. Government of the People's Republic of Bangladesh, Ministry of Agriculture, Office of the Project Director Strengthening Phytosanitary Capasity in Bangladesh Project Plant Quarantine Wing Department of Agriculture Extension Khamarbari, Farmgate, Dhaka; Development Technical Consultants Pvt. Ltd., Dhaka, 1-124.

[17] Nishat, S., Hamim, I., Khalil, M.I., Ali, M.A., Hossain, M.A., Meah, M.B. and Islam, M.R. (2015) Genetic Diversity of The Bacterial Wilt Pathogen Ralstonia solanacearum Using a RAPD Marker. Comptes Rendus Biologies, 338, 757-767. https://doi.org/10.1016/j.crvi.2015.06.009

[18] Ahmed, N.N., Islam, M.R., Hossain, M.A., Meah, M.B. and Hossain, M.M. (2013) Determination of Races and Biovars of Ralstonia solanacearum Causing Bacterial Wilt Disease of Potato. Journal of Agricultural Science, 5, 86-93. https://doi.org/10.5539/jas.v5n6p86

[19] Karim, Z. (2017) Study on Phenotypic Conversion, Virulence and Biovar Expression of Ralstonia solanacearum Causing Potato Wilt and its Management. A Ph.D. Dissertation, Department of Plant Pathology Sher-e-Bangla Agricultural University (SAU), Dhaka, 1-216.

[20] Champoiseau, P.G., Jones, J.B., Momol, T.M., Ji, P., Norman, D.J., Miller, S.A., Schubert, T., Bell, D., Floyd, J.P., Kaplan, D. and Bulluck, R. (2010) Recovery Plan for Ralstonia solanacearum Race 3 Biovar 2: Causing Brown Rot of Potato, Bacterial Wilt of Tomato, and Southern Wilt of Geranium.

https://www.ars.usda.gov/ARSUserFiles/00000000/opmp/RalstoniaR3b2May2010.p df

[21] Danks, C. and Barker, I. (2000) On-Site Detection of Plant Pathogens Using Lateral Flow Devices. EPPO Bulletin, 30, 421-426.

https://doi.org/10.1111/j.1365-2338.2000.tb00922.x

[22] Kinyua, Z.M., Miller, S.A., Chin, M.A. and Subedi, M.N. (2014) Bacterial Wilt Disease Ralstonia solanacearum. Standard Operating Procedure for Use in Diagnostic Laboratories. Version: EA-SOP-RS1. International Plant Diagnostic Network, 1-24. https://ipmil.cired.vt.edu/wp-content/uploads/2014/06/SOP-Ralstonia-solanacerum -EastAfricaFinal-Apr2014-2.pdf

[23] Elphinstone, J.G., Hennessey, J.K., Wilson, J.K. and Stead, D.E. (1996) Sensitivity of Different Methods for the Detection of Pseudomonas solanacearum in Potato Tuber Extracts. EPPO Bulletin, 26, 663-678. https://doi.org/10.1111/j.1365-2338.1996.tb01511.x

[24] Kelman, A. (1954) The Relationship of Pathogenicity in Pseudomonas solanacearum to Colony Appearance on a Tetrazolium Medium. Phytopathology, 44, 693-695.

[25] Goszczynska, T., Serfontein, J.J. and Serfontein, S. (2000) Introduction to Practical Phytobacteriology. ARC-Plant Protection Research Institute, Pretoria.

[26] Aminuzzaman, F.M., Hossain, I. and Ahmed, F. (2010) Cultural Variation and Pa- 
thogenicity of Bipolaris sorokiniana on Wheat in Bangladesh. International Journal of Agriculture, Environment and Biotechnology, 3, 93-98.

[27] Janse, J.D. (1991) Infra- and Intraspecific Classification of Pseudomonas solanacearum Strains, Using Whole Cell Fatty Acid Analysis. Systematic and Applied Microbiology, 14, 335-345. https://doi.org/10.1016/S0723-2020(11)80307-3

[28] Klement, Z., Farkas, G.L. and Lovrekovich, L. (1964) Hypersensitive Reaction Induced by Phytopathogenic Bacteria in the Tobacco Leaf. Phytopathology, 54, 474-477.

[29] Schaad, N.W. (1980) Laboratory Guide for the Identification of Plant Pathogenic Bacteria. American Phytopathological Society, Saint Paul, 28-45.

[30] Suslow, T.V., Schroth, M.N. and Isaka, M.H. (1982) Application of Rapid Method for Gram Differentiation of Plant Pathogenic and Saprophytic Bacteria without Staining. Phytopathology, 72, 917-918. https://doi.org/10.1094/Phyto-72-917

[31] Hayward, A.C. (1964) Characteristics of Pseudomonas solanacearum. Journal of Applied Bacteriology, 27, 265-277. https://doi.org/10.1111/j.1365-2672.1964.tb04912.x

[32] Janse, J.D. (1953) Phytobacteriology: Principles and Practice. CABI Publishing, Wageningen, Netherlands. https://www.cabi.org

[33] Opina, N., Tavner, F., Holloway, G., Wang, J.F., Li, T.H., Maghirang, R., Fegan, M., Hayward, A.C., Krishnapillai, V., Hong, W.F., Holloway, B.W. and Timmis, J.N. (1997) A Novel Method for Development of Species and Strain-Specific DNA Probes and PCR Primers for Identifying Burkholderia solanacearum (Formerly Pseudomonas solanacearum). Asia-Pacific Journal of Molecular Biology and Biotechnology, 5, 19-30.

[34] Doughty, C.J. (2003) Instructed SLA: Constraints, Compensation, and Enhancement. In: Doughty, C.J., Long, M.H. (Eds). The Handbook of Second Language Acquisition, Blackwell Publishing Ltd., Malden, 256-310.

https://doi.org/10.1002/9780470756492.ch10

[35] Denny, T.P. and Hayward, A.C. (2001) Ralstonia solanacearum. In: Schaad, N.W., Jones, J.B. and Chun, W., Eds., Laboratory Guide for Identification of Plant Pathogenic Bacteria, 3rd Edition, APS Press, Saint Paul, 151-173.

[36] EPPO (European Plant Protection Organization) (2004) Ralstonia solanacearum. EPPO Bulletin, 34, 173-178. https://doi.org/10.1111/j.1365-2338.2004.00715.x

[37] Kumar, S., Kedarnath, Hamsaveni, N., Gowda, P.H.R., Rohini, I.B., Rangaswamy, K.T. and Achari, R. (2017) Isolation and Characterization of Ralstonia solanacearum Causing Bacterial Wilt of Solanaceae Crops. International Journal of Current Microbiology and Applied Science, 6, 1173-1190. https://doi.org/10.20546/ijcmas.2017.605.128

[38] Singh, D., Yadav, D.K., Sinha, S., Choudhary, G. (2014) Effect of Temperature, Cultivars, Injury of Root and Inoculums Load of Ralstonia solanacearum to Cause Bacterial Wilt of Tomato. Achieves of Phytopathology and Plant Protection, 47, 1574-1583. https://doi.org/10.1080/03235408.2013.851332

[39] Winstead, N. and Kelman, A. (1952) Inoculation Techniques for Evaluating Resistance to Pseudomonas solanacearum. Phytopathology, 42, 628-634.

[40] He, L.Y., Sequeira, L. and Kelman, A. (1983) Characteristics of Strains of Pseudomonas solanacearum from China. Plant Disease, 67, 1357-1361. https://doi.org/10.1094/PD-67-1357

[41] Schaad, N.W., Jones, J.B. and Chun, W. (2001) Laboratory Guide for the Identification of Plant Pathogenic Bacteria. 3rd Edition, American Phytopathological Society, 
Saint Paul, 1-39.

[42] Elphinstone, J.G. (2005) The Current Bacterial Wilt Situation: A Global Overview. In: Allen, C., Prior, P. and Hayward, A.C., Eds., Bacterial Wilt. the Disease and the Ralstonia solanacearum Species Complex, American Phytopathological Society Press, Saint Paul, 9-28.

[43] Van Elsas, J.D., Kastelein, P, van Bekkum, P., van der Wolf, J.M., de Vries, P.M. and van Overbeek, L.S. (2000) Survival of Ralstonia solanacearum Biovar 2, the Causative Agent of Potato Brown Rot, in Field and Microcosm Soils in Temperate Climates. Phytopathology, 90, 1358-1366.

https://doi.org/10.1094/PHYTO.2000.90.12.1358

[44] Shekhawat, G.S., Chakrabarti, S.K. and Gadewar, A.V. (1992) Potato Bacterial Wilt in India. Indian Council of Agricultural Research, India. Technical Bulletin, 38, 16-39.

[45] Swanson, J.K., Yao, J., Tans-Kersten, J. and Allen, C. (2005) Behavior of Ralstonia solanacearum Race 3 Biovar 2 during Latent and Active Infection of Geranium. Phytopathology, 95, 136-143. https://doi.org/10.1094/PHYTO-95-0136

[46] Kelman, A. (1998) One Hundred and One Years of Research on Bacterial Wilt. In: Prior, P.H., Allen, C. and Elphinstone, J., Eds., Bacterial Wilt Disease: Molecular and Ecological Aspects, Springer, Berlin, Heidelberg, 1-5. https://doi.org/10.1007/978-3-662-03592-4_1

[47] Milling, A., Meng, F., Denny, T.P. and Allen, C. (2009) Interactions with Hosts at Cool Temperature, not Cold Tolerance, Explain Unique Epidemiology of Ralstonia solanacearum Race 3 Biovar 2. Phytopathology, 99, 1127-1134. https://doi.org/10.1094/PHYTO-99-10-1127

[48] Kovacs, N. (1956) Identification of Pseudomonas solanacearum by the Oxidase Reaction. Nature, 178, 703. https://doi.org/10.1038/178703a0

[49] Fahy, P.C. and Persley, G.J. (1983) Plant Bacterial Diseases, a Diagnostic Guide. In: Fahy, P.C and Haywad, A.C., Eds., Media and Methods for Isolation and Diagnostic Tests, Acadamic Press, New York, 369-370.

[50] Hugh, R. and Leifson, E. (1953) The Taxonomic Significance of Fermentative Versus Oxidative Metabolism of Carbohydrates by Various Gram-Negative Bacteria. Journal of Bacteriology, 66, 24-26. https://doi.org/10.1128/jb.66.1.24-26.1953

[51] Eden-Green, S. (1995) A Brief History of Lethal Yellowing Research. In: Oropeza, C., Howard, F.W. and Ashburner, G.R., Eds., Lethal Yellowing Research and Practical Aspects, Kluwer Academic Publishers, Dordrecht, 17-33. https://doi.org/10.1007/978-94-011-0433-3_2

[52] Messiha, N.A.S. (2006) Bacterial Wilt of Potato (Ralstonia solanacearum Race 3, Biovar 2): Disease Management, Pathogen Survival and Possible Eradication. Wageningen University, Wageningen, 1-164.

[53] Chamedjeu, R. R., Masanga, J., Matiru, V. and Runo, S. (2018) Isolation and Characterization of Ralstonia solanacearum Strains Causing Bacterial Wilt of Potato in Nakuru County of Kenya. African Journal of Biotechnology, 17, 1455-1465. https://doi.org/10.5897/AJB2018.16659

[54] Izadiyan, M. and Taghavi, S.M. (2013) Host Range Variation and Genetic Diversity of Iranian Isolates of Ralstonia solanacearum from Potato and Tomato with RAPD and (GTG) 5-PCR. Journal of Plant Pathology, 95, 87-97.

[55] Mollae, A., Hosseinipour, A., Azadvar, M., Massumi, H. and Ebrahimi, F. (2020) Phylotype and Sequevar Determination and AFLP Fingerprinting of Ralstonia solanacearum Strains Causing Bacterial Wilt of potato in South-Eastern Iran. Euro- 
pean Journal of Plant Pathology, 157, 389-402.

https://doi.org/10.1007/s10658-020-02018-5

[56] Karim, Z. and Hossain, M.S. (2018) Management of Bacterial Wilt (Ralstonia solanacearum) of Potato: Focus on Natural Bioactive Compounds. Journal of Biodiversity Conservation and Bioresource Management, 4, 73-92.

https://doi.org/10.3329/jbcbm.v4i1.37879

[57] Buddenhagen, I., Sequeira, L., and Kelman, A. (1962) Designation of races in Pseudomonas solanacearum. Phytopathology, 52, 7263-774.

[58] Rahman, M.F., Islam, M.R., Rahman, T. and Meah, M.B. (2010) Biochemical Characterization of Ralstonia solanacearum Causing Bacterial Wilt of Brinjal in Bangladesh. Journal of Progressive Agriculture, 21, 9-19.

https://doi.org/10.3329/pa.v21i1-2.16744 